\title{
A Multifunctional Hot Structure Heatshield Concept for Planetary Entry
}

\author{
Sandra P. Walker ${ }^{*}$ Kamran Daryabeigi ${ }^{\dagger}$, and Jamshid A. Samareh ${ }^{\ddagger}$ \\ NASA Langley Research Center, Hampton, Virginia, 23681 \\ Robert Wagner ${ }^{\S}$ \\ Northrop Grumman Corporation, Hampton, Virginia 23681 \\ Allen Waters** $^{* *}$ \\ Analytical Mechanics Associates, Hampton, Virginia 23681
}

\begin{abstract}
A multifunctional hot structure heatshield concept is being developed to provide technology enhancements with significant benefits compared to the current state-of-the-art heatshield technology. These benefits can potentially enable future planetary missions. The concept is unique in integrating the function of the thermal protection system with the primary load carrying structural component. An advanced carbon-carbon material system has been evaluated for the load carrying structure, which will be utilized on the outer surface of the heatshield, and thus will operate as a hot structure exposed to the severe aerodynamic heating associated with planetary entry. Flexible, highly efficient blanket insulation is sized for use underneath the hot structure to maintain required operational internal temperatures. The approach followed includes developing preliminary designs to demonstrate feasibility of the concept and benefits over a traditional, baseline design. Where prior work focused on a concept for an Earth entry vehicle, the current efforts presented here are focused on developing a generic heatshield model and performing a trade study for a Mars entry application. This trade study includes both structural and thermal evaluation. The results indicate that a hot structure concept is a feasible alternative to traditional heatshields and may offer advantages that can enable future entry missions.
\end{abstract}

\section{Introduction}

$\mathrm{H}^{\mathrm{s}}$ EAT shields are a critical component on planetary entry vehicles providing the thermal protection required on the windward surface of the vehicle. Heatshields are necessary to survive the severe aerodynamic heating environment which occurs when the vehicle traveling from space enters the atmosphere of a planet. Traditional heatshield designs include the use of thermal protection system (TPS) materials on the outer most windward surface of the vehicle. Typically, these TPS materials are designed to ablate and thus reduce heat transfer through the material to the underlying structure. ${ }^{1}$ The TPS materials are then bonded to a carrier structure.

The most recent state-of-the-art (SOA) heatshields have utilized materials designed to ablate. The Mars Science Laboratory (MSL) used phenolic impregnated carbon ablator (PICA) for the first time on a Mars entry vehicle as the heatshield TPS material. ${ }^{2,3}$ Similarly, for returning to Earth from the International Space Station (ISS), SpaceX has utilized PICA-X, a derivative of PICA, on their Dragon spacecraft capsule heatshield. ${ }^{\dagger \dagger}$

NASA has a great need for developing innovative entry vehicle decelerator systems for delivering higher payload masses to other planetary systems. Hypersonic Inflatable Aerodynamic Decelerator (HIAD) concepts are currently being developed at NASA. ${ }^{4}$ Flexible insulative TPS presently developed for HIAD concepts is limited to a

\footnotetext{
* Assistant Branch Head and Research Aerospace Engineer, Structural Mechanics and Concepts Branch, MS 190.

${ }^{\dagger}$ Research Aerospace Engineer, Structural Mechanics and Concepts Branch, MS 190, Senior Member.

* Aerospace Engineer, Vehicle Analysis Branch, MS 451, Associate Fellow.

$\S$ Engineer, Northrop Grumman Corporation

${ }^{* * *}$ Lead, Structural Mechanics, Analytical Mechanics Associates

${ }^{\dagger \dagger}$ http://www.spacex.com/sites/spacex/files/pdf/DragonLabFactSheet.pdf [cited 18 November 2013]
} 
maximum entry heating rate of $75 \mathrm{~W} / \mathrm{cm}^{2}$ to $100 \mathrm{~W} / \mathrm{cm}^{2}$, therefore requiring large decelerator diameters of $10 \mathrm{~m}$ to $15 \mathrm{~m}$, thus limiting the application of this TPS to missions with low to medium entry velocities. Use of flexible ablative TPS for HIAD concepts could potentially withstand heating rates up to $200 \mathrm{~W} / \mathrm{cm}^{2}$ with corresponding shorter aerocapture/entry durations; and thus require a smaller decelerator diameter of $5 \mathrm{~m} .{ }^{5}$ Even though flexible ablative and insulative TPS HIAD concepts are very promising, they may not be able to cover the entire design space needed for various planetary entry systems. Recently, researchers have studied a hypersonic rigid deployable decelerator. $^{6}$

A novel approach to a heatshield design, the multifunctional hot structure (HOST) heatshield concept is proposed for the purpose of providing a more efficient heatshield to enable future planetary missions. The HOST concept could be considered for a heatshield on a capsule with or without the additional use of rigid deployable decelerators depending on future mission requirements, including aerocapture. A building block approach is being followed to develop the concept to assess feasibility. Consequently, the preliminary development initiated with a focus on only the capsule heatshield, i.e., the heatshield without rigid deployable extensions, for an ISS return application. ${ }^{7}$ This work included a trade study comparing the HOST concept to a traditional heatshield design. The initial results indicated that the HOST concept has the potential to save both mass and volume with significantly less recession compared to traditional heatshield designs. For the current study, critical material property testing is performed to address concerns with high stresses identified in the preliminary structural analysis which would also be needed for further applications. Then, the focus of the effort turns to considering a Mars entry application and using an MSL-type heatshield for a baseline design to compare the HOST concept. A structural analysis model is developed for the trade study. Thermal evaluation for Mars entry conditions is also conducted through preliminary arc-jet testing and thermal analysis. The results of this current effort to develop a multifunctional HOST heatshield concept are presented in this paper.

\section{Concept Overview}

The HOST concept is being pursued to enable future planetary missions with precision landing by providing a more efficient alternative heatshield concept. The current SOA in space vehicle heatshield technology separates the function of the TPS from the primary load carrying structure. This design approach is based on heritage TPS materials which traditionally are either ablative materials or ceramic tile insulation. Because these materials are extremely brittle, with very low load carrying capability, the design approach is to isolate the TPS from the structural loads. ${ }^{8}$ This has traditionally been accomplished for Earth entry missions by introducing a strain isolation pad (SIP) layer between the TPS and carrier structure.

For the initial ISS return study, PICA was selected as the TPS material with the SIP layer bonded to both the TPS material and carrier structure using room temperature vulcanizing (RTV) adhesive. The carrier structure is a titanium honeycomb sandwich construction. For the Mars entry study currently being pursued, the MSL heatshield is considered for use in developing a baseline heatshield concept. MSL also utilizes PICA for the TPS material on the outer mold line (OML). The carrier structure is composed of a composite honeycomb sandwich construction. More details on the MSL-type baseline heatshield concept will be given in the next section.

The HOST concept is unique in integrating the TPS with the underlying carrier structure. Through integration of functions both mass and volume requirements within the spacecraft have the potential to be decreased. This approach requires a thorough understanding of the thermal-structural response of the heatshield subject to the aeroheating associated with planetary entry. A ceramic matrix composite (CMC) material system is required for use as primary load carrying structure on the OML of the heatshield as illustrated in Fig. 1. Then flexible, highly efficient blanket insulation can be sized underneath the CMC to achieve the desired inner mold line (IML) temperatures. This combination is a unique concept which exploits the CMC material system capabilities by having TPS material components also serve as primary load carrying structure. CMCs are needed for HOST due to their unique ability to carry significant structural loads up to extreme temperatures approaching $1649^{\circ} \mathrm{C}\left(3000^{\circ} \mathrm{F}\right)$ while remaining relatively lightweight. Currently, CMCs have not been utilized in applications as primary load carrying structure on aerospace vehicles.

An advanced carbon-carbon-6 (ACC-6) was the material chosen as the $\mathrm{CMC}$ outer layer to serve as the primary load carrying structure component of the HOST heatshield. ${ }^{9}$ ACC- 6 was selected due to the availability of a material property database and the cost. This material was under consideration in a Defense Advanced Research Projects Agency (DARPA) program where the material property database was generated. ${ }^{10}$ Although more advanced CMCs may be considered eventually which may offer additional structural capability and integrity, the availability of their material properties were limited, so the decision was made to initiate this work with the ACC-6 material system. 
For the HOST concepts, the whole system is integrated in serving as the TPS. The ACC-6 outermost layer also serves as the primary load carrying structure. The need for adhesive bonding the TPS to the structure is eliminated, thus eliminating bond line integrity and stress concentration issues, which can precipitate premature failures. Alternatively, other methods can be used to hold the internal insulation in place via the structural designs considered. The highly efficient blanket insulations being evaluated are discussed in detail in a subsequent section.

The HOST concept can also be utilized as the

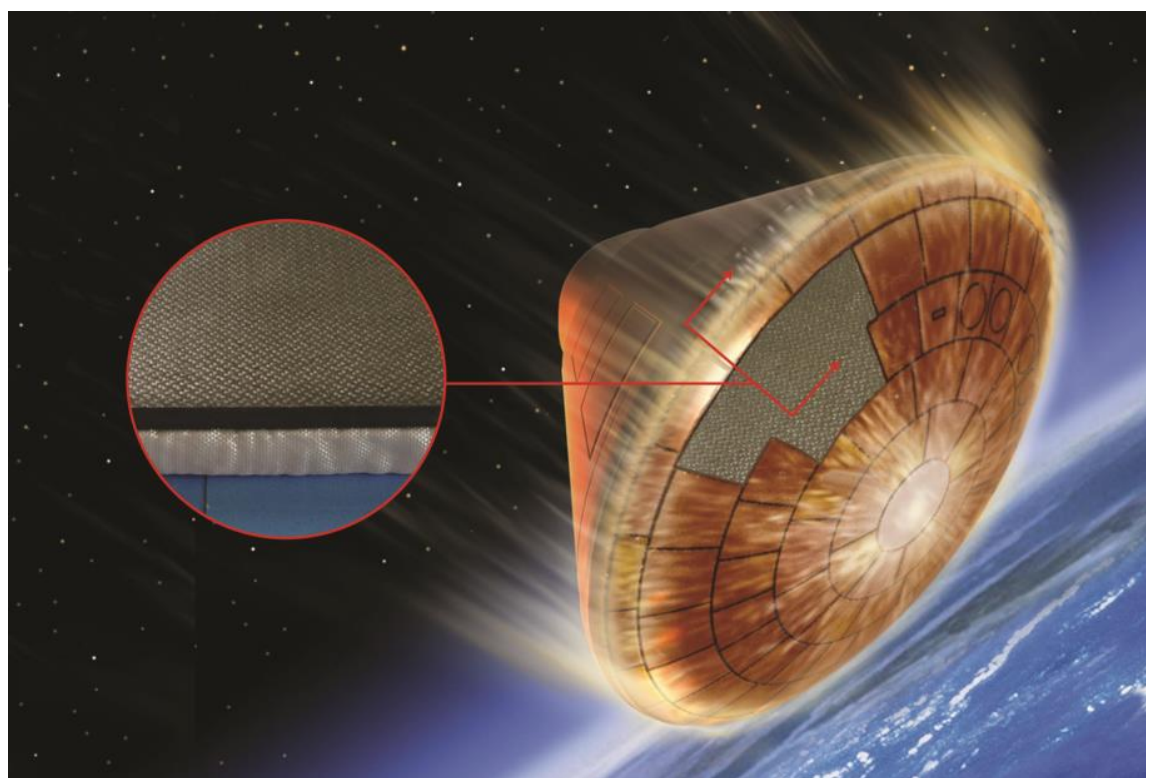

Figure 1. Illustration of a multifunctional HOST heatshield concept for an Earth entry application and a close-up of the carbon-carbon outer layer with a blanket insulation underneath.

capsule heatshield in a rigid deployable system. The technology can be extended to include deployable extension components for missions requiring additional deceleration. In following a building block approach to evaluating feasibility of the HOST concept, this preliminary study focuses only on the capsule heatshield.

If successful, the HOST concept could lower mass and volume and be reusable. The concept may also facilitate high precision landing through less recession, ensuring greater dimensional stability, and/or through improved center of gravity location. Although, there is risk in develoment compared to the demonstrated current technology available, the payoff could be enabling for advanced missions. The development effort will need to include evaluation of the combined thermal-structural response of the HOST heatshield to thoroughly evaluate the performance of the concept along with fabrication and testing of unique carbon-carbon hardware. Both cost and schedule are a concern for fabricating advanced carbon-carbon hardware due to the unique application. Therefore, a building block approach to development of the HOST concept is being pursued with first performing analyses to develop preliminary designs to compare with SOA baseline designs. Also, some early evaluation of the concept is being addressed with coupon level test specimens. Through addressing the critical concerns on the feasibility of the HOST concept with relatively inexpensive coupon level thermal and structural testing that is being conducted along with performing the thermal and structural analyses to verify feasibility, the development of the HOST concept can efficiently progress and potentially offer an enabling alternative heatshield concept for future planetary missions.

\section{Structural Evaluation for Mars Entry}

\section{A. Critical Material Property Testing}

During the initial structural design evaluation of an ISS return heatshield concept performed in the prior study (see Ref. 7), results showed high local stresses in the ACC-6 material in the vicinity of the attachment points in the finite element model (FEM). These high stresses were occurring in the outer fibers of the T-beam stiffeners being modeled as beam elements, which were experiencing significant bending. Since typically outermost bending stresses were over-predicted with finite element analyses (FEA), and flexural strength properties were not included in the available material property database for ACC-6, flexural testing of coupon ACC-6 specimens were conducted. Fourpoint bend tests were performed on both ACC- 6 thicknesses of interest from the preliminary study, $6.35 \mathrm{~mm}$ and $12.7 \mathrm{~mm}$. Results of the testing provided average flexural strength properties. ${ }^{11}$ In general, the flexural strength of the ACC- 6 material was determined to be $30 \%$ greater than the average tension and compression strength of the material. This additional flexural strength property will be included in the current structural evaluation of the HOST concept. 


\section{B. Generic Analysis Model}

The MSL entry capsule vehicle was selected in this paper for consideration as the SOA for a Mars entry application. Thus, MSL formed the basis for construction of a generic model to structurally evaluate a HOST concept and compare results directly to a traditional MSL-type heatshield design, which was designated as the baseline design. The generic model utilizes some MSL design information to construct a model to evaluate alternative heatshield concepts, although some assumptions and variations are made to keep the model generic and simple for this study. Consequently, the generic model should provide a good foundation to compare the baseline heatshield design with an alternative HOST concept design for a Mars entry application, and thus a means of evaluating the feasibility and possible benefits of the HOST concept for Mars entry.

The construction of the generic model is based on a traditional MSL-type heatshield for Mars entry. The MSL entry vehicle geometry used for the generic model is displayed in Fig. 2 along with a photograph showing the actual PICA tiles on MSL. ${ }^{12}$

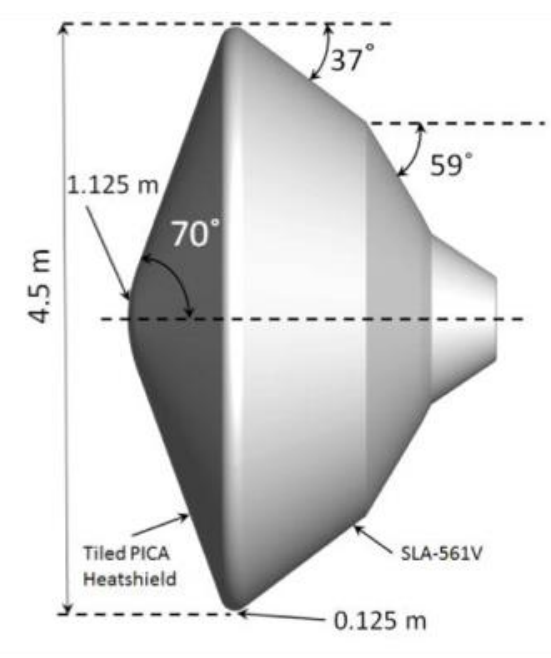

(a)

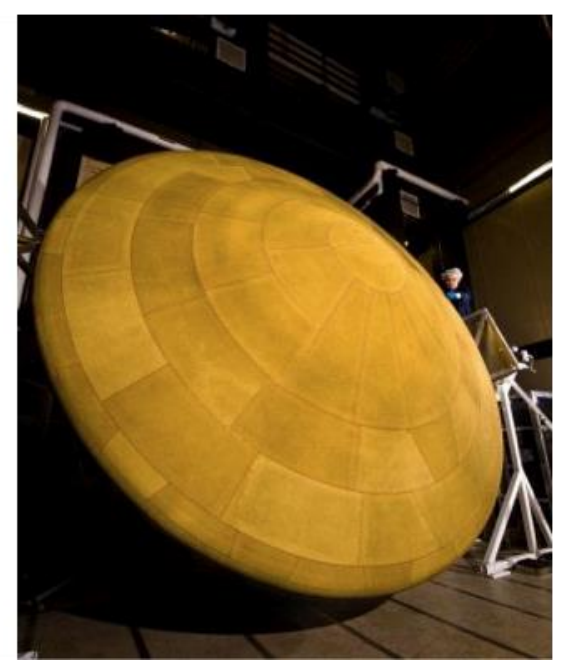

(b)

Figure 2. (a) MSL geometry and (b) photograph of PICA tiles on MSL heatshield (taken from Ref. 12).

A simplified FEM is generated for the generic heatshield based on the MSL entry vehicle design with a mass of $3257 \mathrm{~kg} .{ }^{13}$ The model geometry attributes for this analysis effort is displayed in Fig 3. The 4.5-m diameter heatshield is comprised of a spherical center section, a cone area section, and a shoulder section. In Fig. 3, the shoulder section of the heatshield is shown in red and the additional ring frame modeled is shown in blue.

MSC Patran/Nastran were employed in generating the FEM. ${ }^{14}$ The elements contained in the FEM are displayed in Fig. 4. The center of gravity (CG) location for the current model was chosen based on the actual MSL CG coordinates ${ }^{15}$ However, the generic model CG was shifted slightly to be centered with respect to the z-coordinate to keep the geometry axi-symmetric, and thus simplified for this preliminary study. A concentrated mass element (CONM2) was located at the CG in the FEM. The CONM2 element mass value consisted of the mass of the capsule less the heatshield mass. The heatshield and ring frame are constructed of shell elements (CQUAD4). For simplicity, the ring frame is assumed to have the same structural stiffness as the heatshield sandwich structure and is included in the model to distribute load reacted in the shoulder region to a ring frame in a capsule design. At the intersection of the ring frame and heatshield elements, 6-degree-of-freedom springs (CBUSH) are used to connect the heatshield to a backshell ring frame (CBEAM), which is modeled as an aluminum L-bracket. The backshell ring frame is further connected by rod elements (CROD) that connect to a concentrated mass (CONM2) at the CG. Only the heatshield shell elements are modeled accounting for their mass, which includes the spherical area, cone area, and shoulder region. The heatshield ring frame shell elements, the backshell beam elements, and the rod elements are left massless. Also, the stiffness values for the rod elements were adjusted during the baseline analysis effort described in the next section. The updated rod stiffness values were then included as part of the generic model and thus used for all structural analysis results presented. This generic analysis model provides an efficient platform for evaluating 
heatshields for MSL-type entry capsules since only the relevant aspects of the heatshield are included in detail in the model, where the other capsule structural components have been simplified. The generic model can now be utilized for performing trade studies on heatshield concepts. This generic model is used in the forthcoming sections for generating both the baseline analysis model of a traditional MSL-type heatshield design and the HOST concept analysis model, so that the two could be compared in a uniform and thus objective trade study.

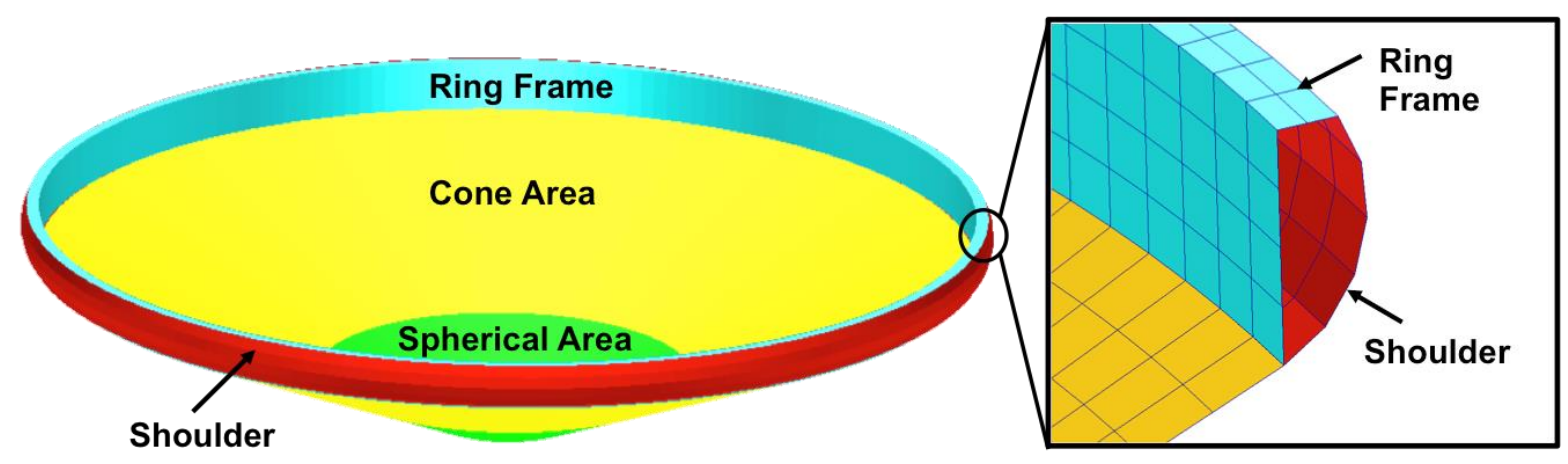

Figure 3. Heatshield model.

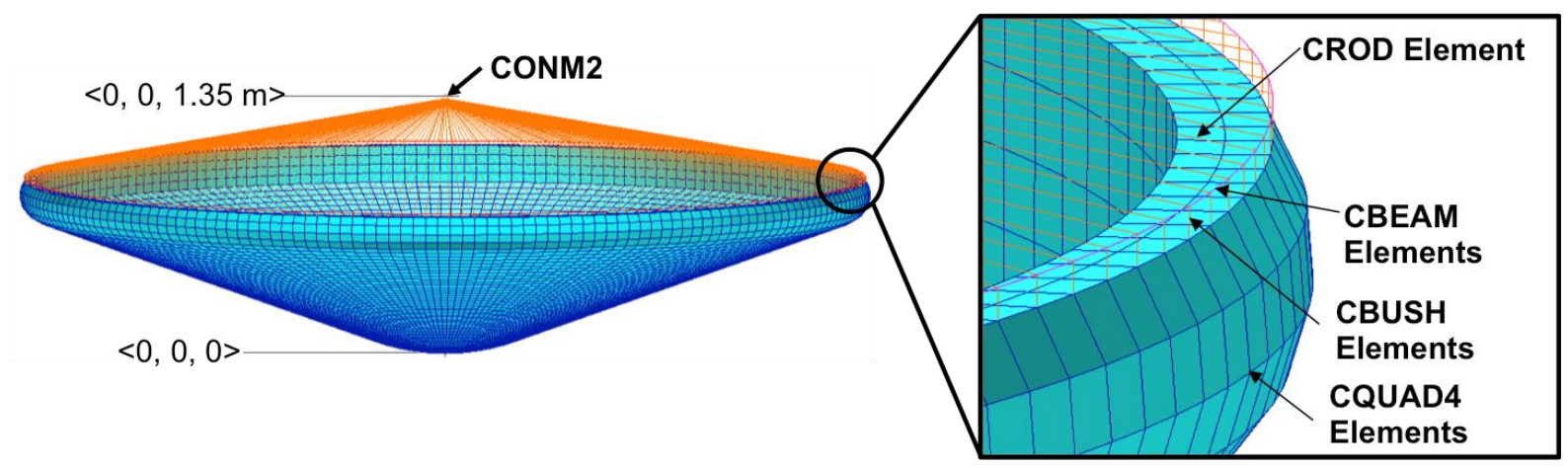

Figure 4. Nastran structural finite element model of Mars entry capsule.

\section{Baseline Structural Analysis}

Starting with the generic model, composition details to complete the baseline model were included in the FEM following the traditional design approach used on the MSL, which consisted of an ablative TPS bonded to an underlying carrier structure. Many of the baseline attributes were identical to the MSL design, however some variations and assumptions were included to keep the model simple and generic. As on MSL, PICA was utilized for the TPS material with a constant thickness of $3.175 \mathrm{~cm}^{2}$ The carrier structure was comprised of a honeycomb sandwich panel with $6.35-\mathrm{cm}$ thick aluminum honeycomb and $0.051-\mathrm{cm}$ thick M55J graphite-polycyanate composite facesheets. ${ }^{16}$ This construction of significantly thick honeycomb with stiff M55J-BCTy-1 graphite cloth facesheets allowed for the PICA tiles to be bonded directly to the aeroshell carrier structure in the MSL design. ${ }^{17}$ That is to say, the need for a SIP layer was deemed unnecessary due to the minimal bending expected with such a thick and stiff structure. A $0.03-\mathrm{cm}$ thick layer of RTV was assumed for bonding the PICA to the carrier structure. The PICA and RTV were included on the heatshield shell elements as non-structural mass. For this baseline heatshield design, the total mass of the heatshield was computed to be $382 \mathrm{~kg}$. Therefore, considering the vehicle mass of $3257 \mathrm{~kg}$, a concentrated CG mass of $2875 \mathrm{~kg}$ was included at the CG location. There were a total of 14,257 elements in the baseline structural model. 
The load case for evaluating the baseline model was the critical load case used to design the MSL heatshield carrier structure, which was a $15-\mathrm{g}$ deceleration occurring when the capsule entered the Martian atmosphere. Applying this $15-\mathrm{g}$ load to the baseline model, the resulting minimum and maximum principle stresses were utilized to generate margin of safety (MS) countour plots using the MS equation displayed in Fig. 5. The MS calculation included a factor of safety (FS) of 1.5, the material allowable stress values, $\sigma$ all, and the predicted FEM prinicple stresses, $\sigma$ FEM. The stiffness of the rods connecting the heatshield to the CG were then adjusted slightly from an initial assumed value until positive MS values were achieved with a minimum value near zero. This resulting MS countour plot with the mimimum MS value of 0.0287 is displayed in Fig. 5. Two MS minimums were observed to occur where one was located at the intersection of the heatshield cone area with the heatshield shoulder and the other was located near the z-direction center of the cone area.

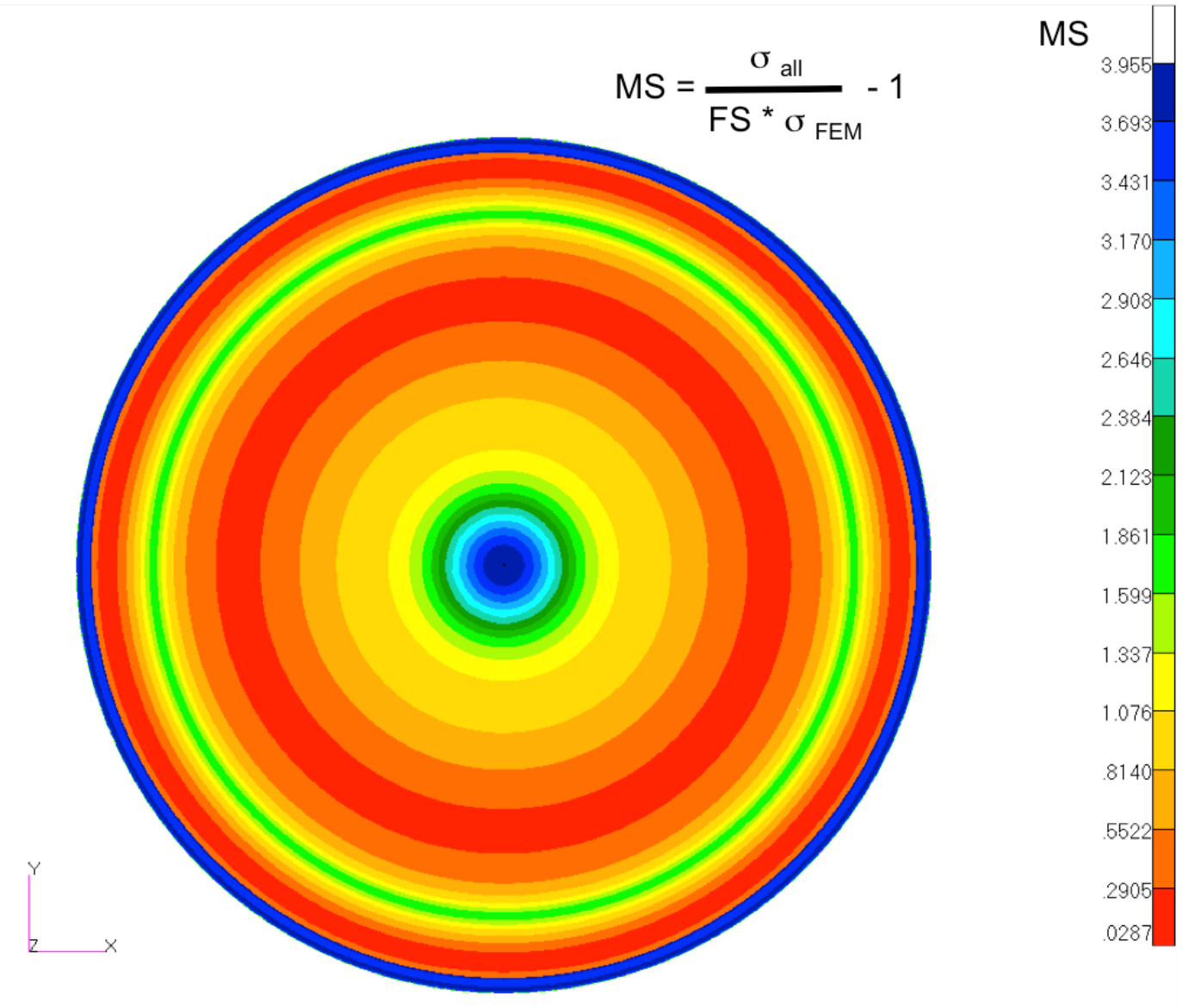

Figure 5. Baseline model margin of safety (MS) contour plot.

The corresponding z-displacemens predicted for the baseline heatshield are displayed in Fig. 6 on a contour plot of the deformed shape. The combined overall z-displacement of the rods and beams connecting the heatshield to the CG was $0.597 \mathrm{~cm}$ while the overall $\Delta \mathrm{z}$ of the heatshield was $0.495 \mathrm{~cm}$. The deformed shape of the heatshield shows that flexure is occurring in the cone area of the heatshield while the shoulder area and spherical areas are significantly less deformed. These results were considered acceptable to provide the basis for further study. 


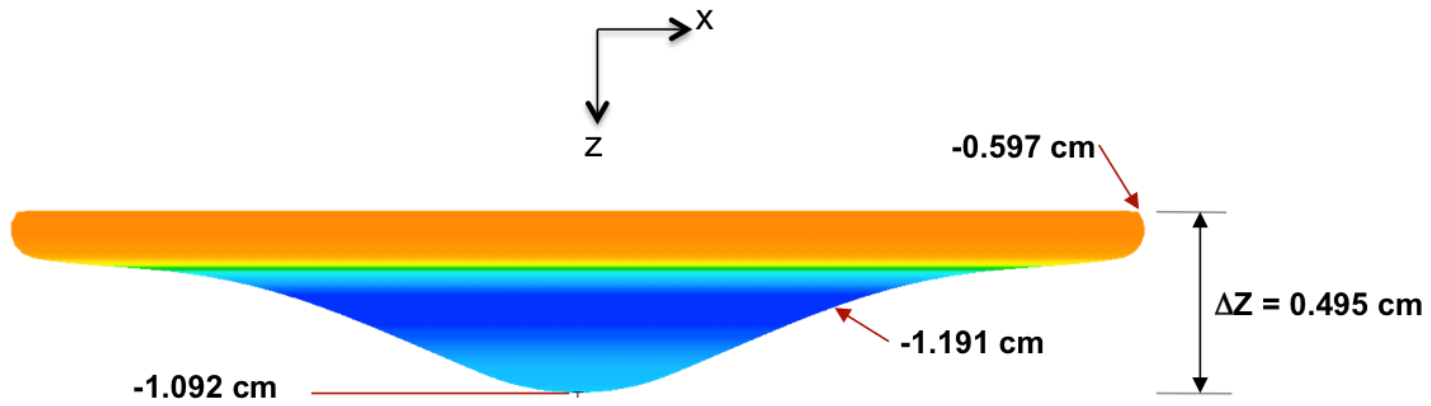

Figure 6. Baseline model z-displacement results.

\section{HOST Structural Analysis}

The HOST heatshield concept being developed for this Mars entry application is initially envisioned to be a frame stiffened hot structure outer aeroshell, with non-structural light weight blanket insulation sized underneath the hot structure skin to maintain required internal temperatures. Development of a HOST structural model for a Mars entry application initiated with adopting the generic model. Only the construction of the heatshield and ring frame were modified for the HOST model. Accordingly, modifications were made to the properties and materials used for the shell elements and additional beam elements are introduced for modeling the frame stiffened construction. For the HOST model, the heatshield structure is constructed of entirely ACC-6 skin and frame stiffeners.

The FEM developed for the HOST analysis effort is shown in Fig. 7 for the heatshield component only. The elements connecting the heatshield to the CG are the same as shown on the generic model in Fig. 4, so are not shown again here. Also, this model included an ACC-6 skin and shoulder ring frame modeled with the same CQUAD4 elements as in the generic model. The blanket insulation areal density is included as non-structural mass on the CQUAD4 entries. In the cone area, the two ACC-6 ring frames and three ACC-6 longitudinal stiffeners are modeled as CBEAM elements, although in Fig. 7 the beam elements are being visualized as solid elements to show the details of their construction. For simplicity with this initial model, all ACC-6 beam elements were constructed as T-stiffeners with the same size web and flanges as shown. The T-stiffener was chosen considering joining and manufactured as an integral stiffener in the fabrication of a seven segment ACC-6 hot structure component. The location and size of the beam T-stiffeners where chosen based on engineering judgment and evaluation of preliminary analysis results. The ACC-6 skin, web, and flange thicknesses were $0.635 \mathrm{~cm}$. The web height was $1.75 \mathrm{~cm}$ and the flange was sized to be $2.54 \mathrm{~cm}$. Again for simplicity, the ACC-6 heatshield and frames are modeled as a single, continuous structural component. Although the T-stiffeners were located based on an assumption that they coincided with joint locations, the analysis model did not include joint details which is planned for future work.

Using the same CG mass and attachment rod stiffness values as the generic and baseline model, structural analysis was performed on the HOST FEM. The first load case evaluated was the same 15 -g deceleration load case considered in the baseline analysis. For the 15-g load case, the preliminary design of the HOST concept resulted in the minimum MS contours on the shell elements displayed in Fig. 8. The minimum MS predicted was 0.295, well above a minimum of near zero. Unlike the baseline results which were uniform around the circumference of the heatshield, for the HOST concept, the minimum occurred very locally at the intersection of the longitudinal Tstiffeners with the shoulder area. The MS values that occur in the beam elements are displayed in Fig. 9. The minimum MS values occurred at the intersection of the radial stiffeners with the outer most ring frame, with a minimum value of 0.82 . Overall, the MS values of the HOST concept indicate that there is potential to further reduce the size and/or number of stiffeners, especially away from the very local peak stress concentrations. However, the thickness of the skin may be needed due to thermal and other considerations, so any additional structural optimization should consider other factors, including fabrication and joining, in achieving an overall optimal heatshield design. Therefore, the current preliminary design will not be further optimized here. 


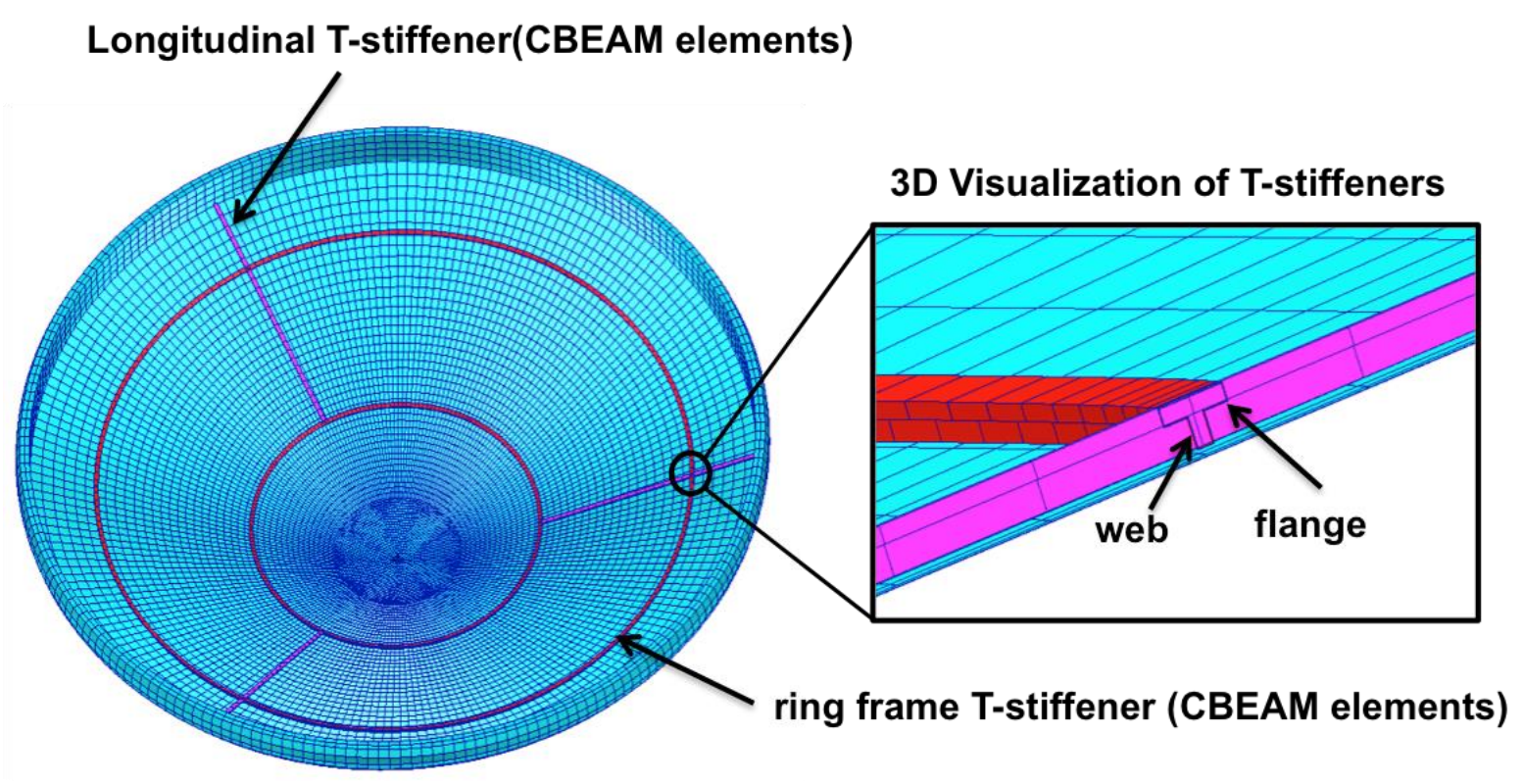

Figure 7. Structural Finite Element Model of HOST heatshield and three-dimensional visualization of T-stiffeners.
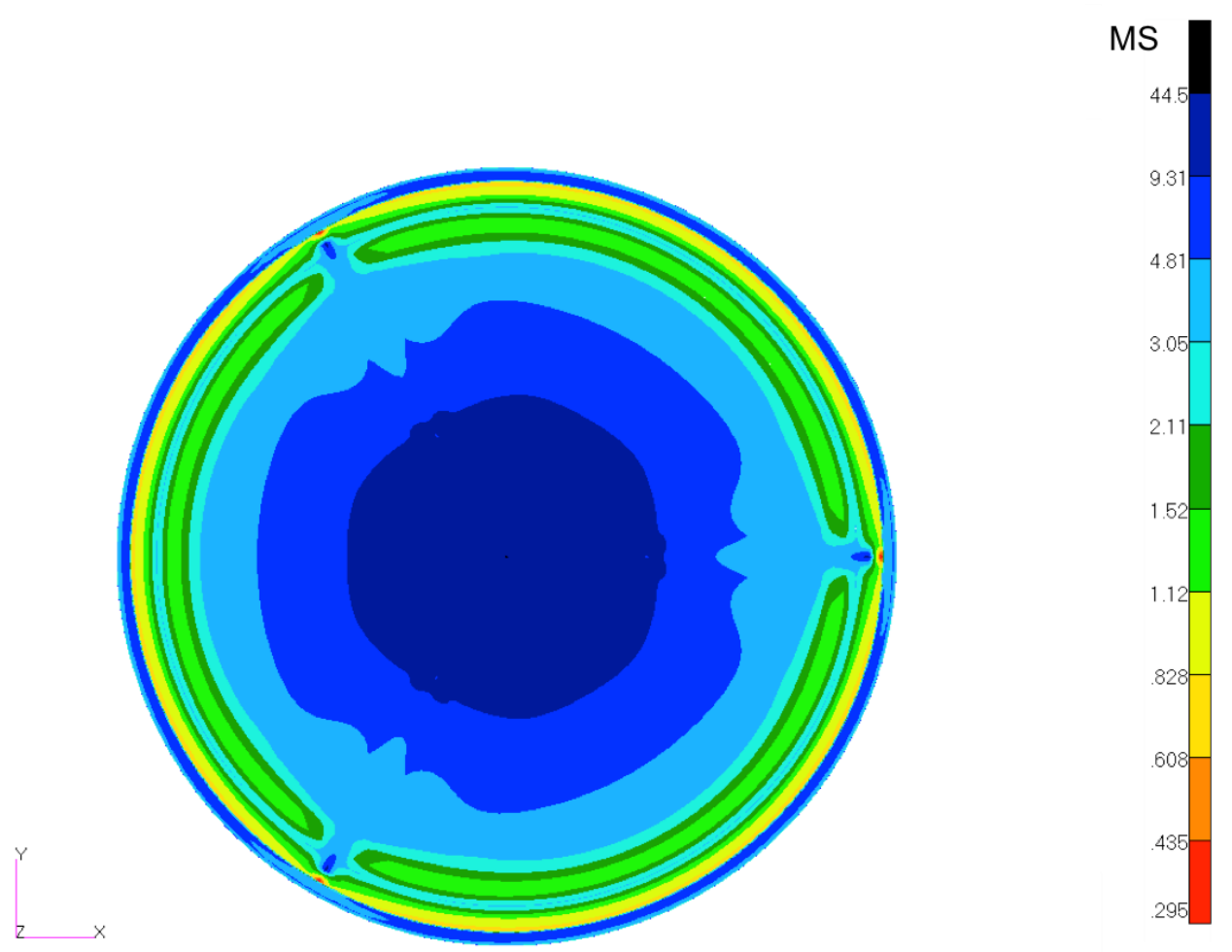

Figure 8. HOST concept margin of safety (MS) contours on heatshield aeroshell (shell elements). 

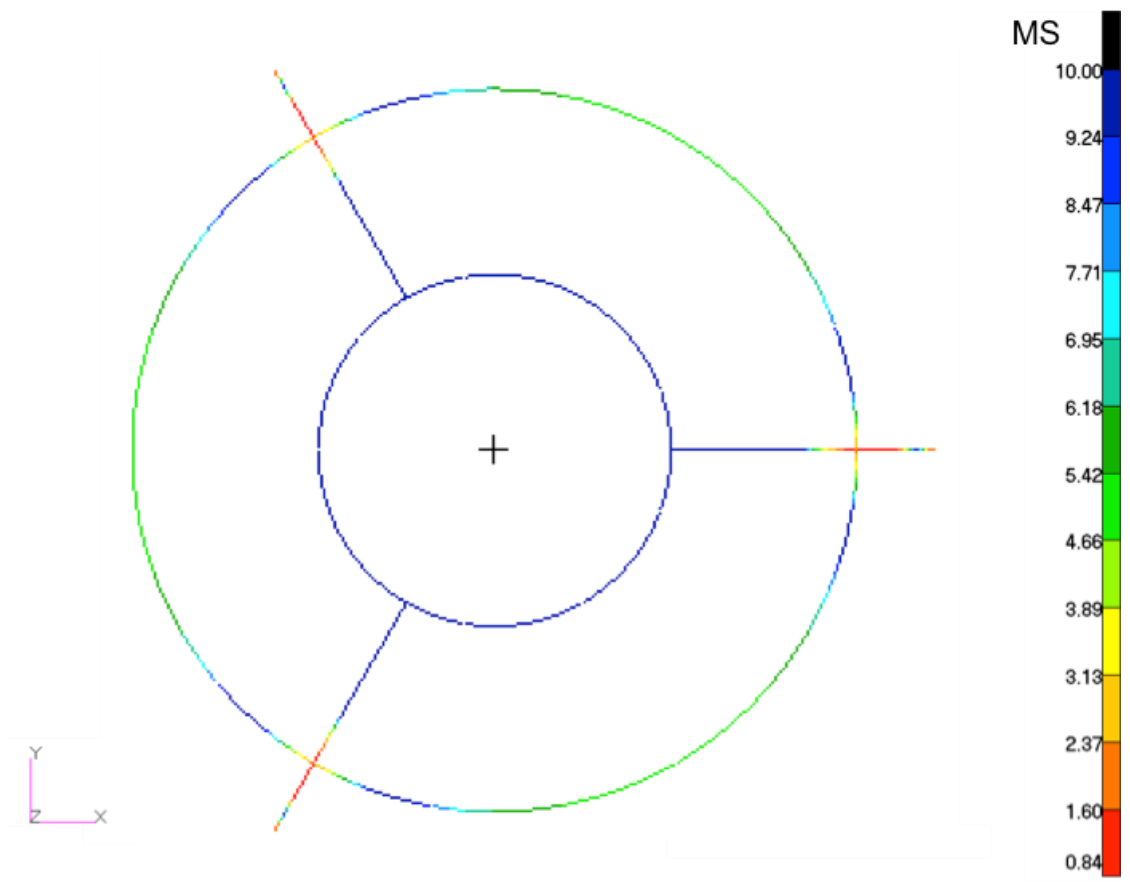

Figure 9. HOST concept margin of safety (MS) contours on frame stiffeners (beam elements).

A convergence study was also performed for the HOST model stress results. Each element in the model was essentially uniformily divided into four elements to generate a refined mesh model. The results of interest occurred at the termination of the axial stiffener, which terminated at the intersection of the cone region with the shoulder region (see Fig. 3 and Fig. 7). Close ups of the shell element results in this region are displayed in Fig. 10-a and Fig. 10 -b where a mirror image of the original mesh region is displayed for the refined mesh region. The results revealed what appears to be a stress singularity at the intersection. In the graph in Fig. 10-c, the $\mathrm{x}$ locations plotted initate at the intersection of the shoulder with the cone. The stresses in the refined mesh elements are compared to the

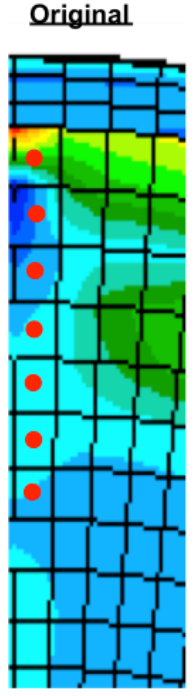

(a)

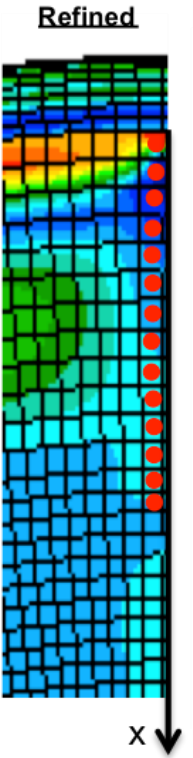

(b)

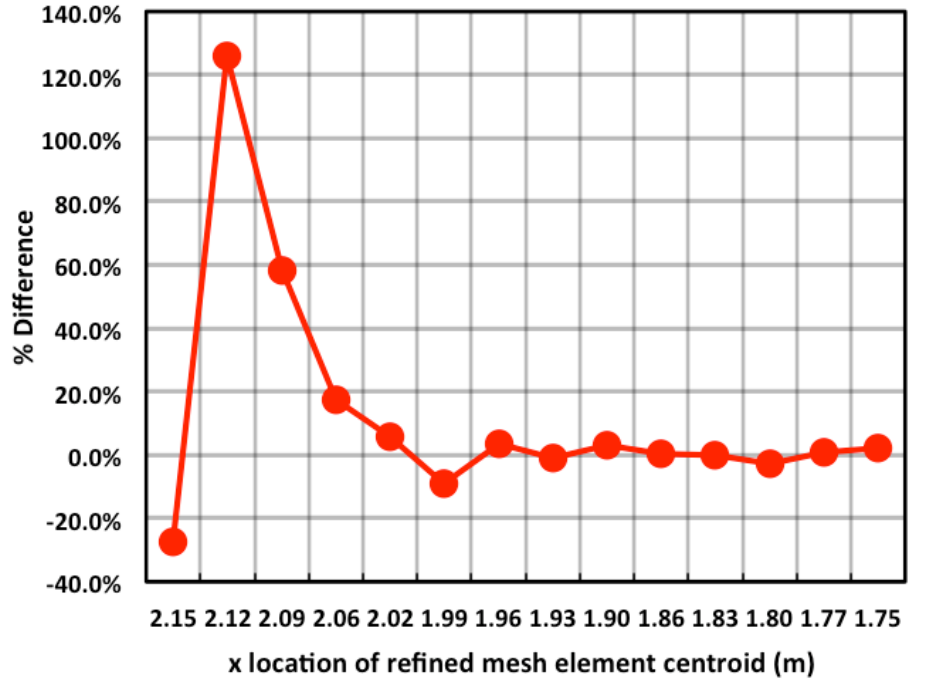

(c)

Figure 10. The (a) original and (b) refined mesh with a (c) plot of the percent difference results. 
stresses in the original mesh, in the element located within the same $\mathrm{x}$-coordinate location, to compute the percent difference. As can be observed in the graph, the percent difference between the HOST original and refined mesh model first changes sign from the element adjacent to the intersection, then quickly dissipates a small distance away from the intersection. In essence, the solution is converged in the model except for this very localized region. Consequently, the stress at the intersection may be singular and should not drive a global design, but the extent of a stress concentration should be considered in a local detailed design effort.

The z-displacements predicted for the HOST model are given in Fig. 11 on a contour plot of the deformed shape. Similar to the baseline results, the deformed shape reveals the majority of deformation is occurring in the cone area of the heatshield where there is less deformation in the shoulder and spherical areas of the heatshield. The peak zdisplacement on the apex of the heatshield was the same value as that predicted for the baseline, where $\mathrm{z}=$ $-1.092 \mathrm{~cm}$. However, the z-displacement of the attachment structure was slightly lower at $-0.490 \mathrm{~cm}$. A slightly greater overall $\Delta \mathrm{z}=0.602 \mathrm{~cm}$ occurred for the HOST heatshield, which was $0.107 \mathrm{~cm}$ greater than the overall $\Delta \mathrm{z}$ for the baseline model.

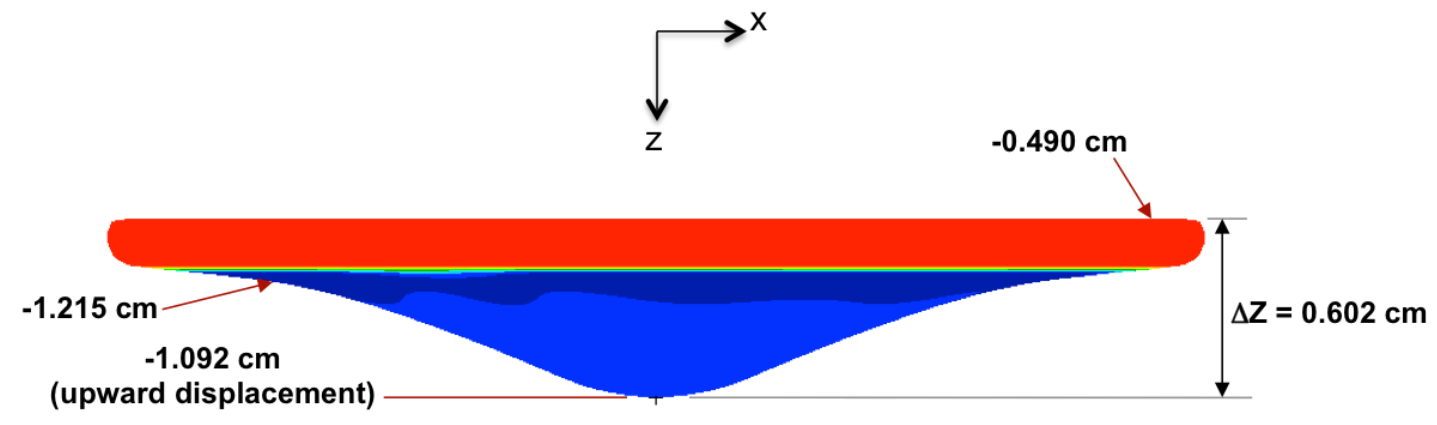

Figure 11. HOST model z-displacement results.

\section{E. Dynamic Modes Evaluation}

Dynamic normal modes analysis was also performed to determine the natural frequency response on both the baseline model and HOST concept heatshield. Considering minimum frequency requirements for payload on a Delta IV launch vehicle, the minimum axial frequency is $27 \mathrm{~Hz}$ and the minimum lateral frequency is $10 \mathrm{~Hz} .{ }^{18}$ In the current modal assessment, a free-free boundary condition was used to perform a modal comparison between the baseline and HOST models. For the baseline, the axial modes began at over $200 \mathrm{~Hz}$ and the lateral mode begins at $33 \mathrm{~Hz}$. For the HOST concept, the axial mode begins at $115 \mathrm{~Hz}$ and the lateral mode begins at $19 \mathrm{~Hz}$. These results indicated that dynamic modes do not govern the design of the heatshield for either the baseline or HOST concept.

\section{Thermal Evaluation for Mars Entry}

\section{A. Mars Entry Environment}

The aerothermal heating environments for typical Mars entry missions were of interest for initiating the thermal evaluation effort. Accordingly, the Mars heating profiles generated here are based on preliminary MSL trajectory reconstruction. ${ }^{15}$ The Mars entry trajectory is based on a $4.5 \mathrm{~m}$ diameter MSL vehicle shown in Fig. 2 with entry velocity of $5.9 \mathrm{~km} / \mathrm{sec}$. The reconstruction data is used to create a cold-wall heating profile using the Sutton-Graves approximation. ${ }^{19}$ The heat flux variation with time generated from the Sutton-Graves approximation is shown in Fig. 12., which corresponds to the stagnation heating profile generated from the initial assessment of MSL flight data. Three additional parametric curves are also shown in the figure. The Sutton-Graves cold-wall heating profile was scaled to generate a profile with maximum heat flux of $100 \mathrm{~W} / \mathrm{cm}^{2}$ which corresponded with the peak heat flux profile predicted for MSL in the shoulder region. To evaluate the HOST heatshield for possible future Mars missions which may incur higher peak heating than MSL, the profile was also scaled to peak heat flux values of 150 $\mathrm{W} / \mathrm{cm}^{2}$ and $200 \mathrm{~W} / \mathrm{cm}^{2}$ for this study. Note the current Mars entry trajectory included jettisoning the heatshield prior 
to landing, similar to MSL entry. Also, the peak surface pressure predicted to occur during MSL entry was $0.3 \mathrm{~atm}$ with a variation similar to the parametric curves in Fig. 12, but with the peak occurring approximately $10 \mathrm{sec}$ before the peak heat flux. ${ }^{12}$

\section{B. Thermal Testing}

Preliminary testing has been conducted on coupon heatshield material samples to demonstrate thermal performance when subjected to Mars entry aeroheating conditions. Since ACC- 6 is being considered as the outermost layer material for the HOST concept and PICA was used as the outermost layer material on MSL, both materials were tested with the same conditions to get a direct comparison on thermal performance. The Hypersonic Materials Environmental Test System (HYMETS) arc-jet facility at NASA LaRC as shown in Fig. 13 was chosen for testing due to the ability to test small 25.4$\mathrm{mm}$ diameter specimens in an environment simulating entry into the Mars atmosphere shown in Fig. $14 .^{20}$

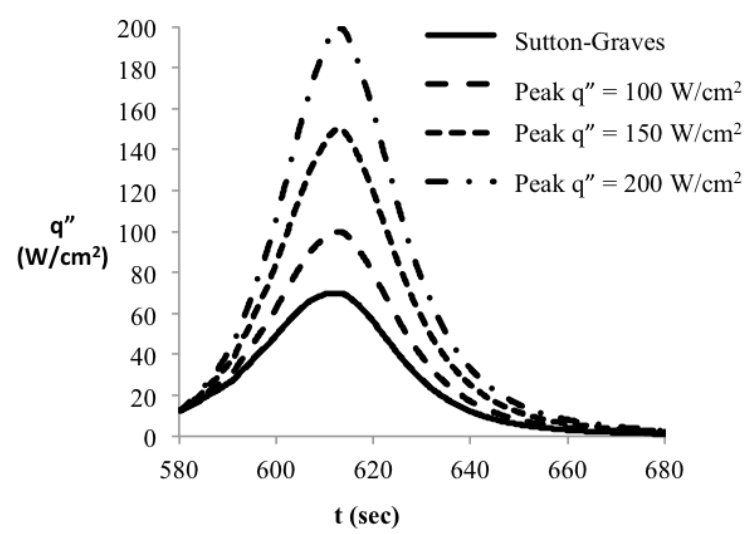

Figure 12. Parametric Mars entry heating profiles.

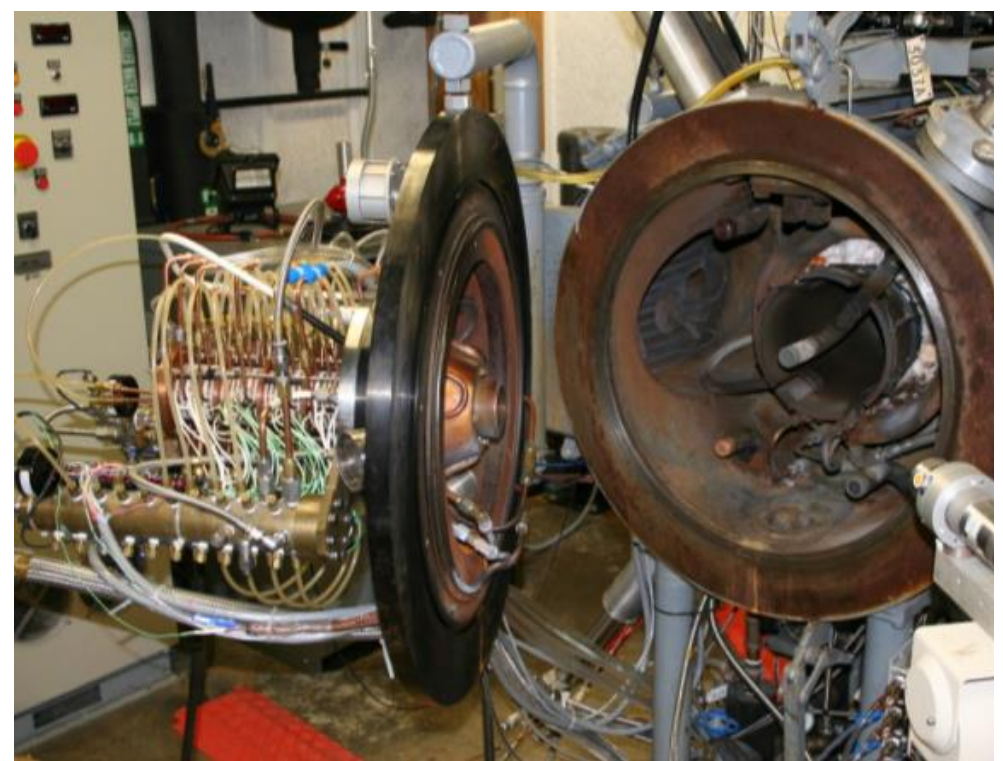

Figure 13. Photographs of the HYMETS arc-jet facility with the test chamber door open. (taken from Ref. 20 )

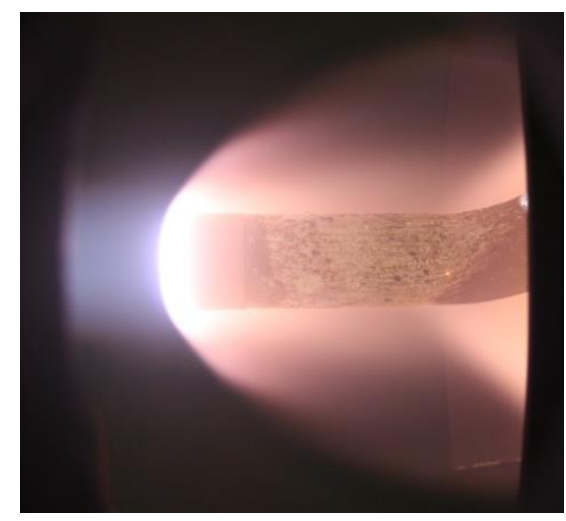

Figure 14. Photograph of a specimen mounted on a sting being tested in HYMETS in a simulated Martian atmosphere entry.

A constant heating pulse for a duration where the total integrated heat load matched that of the actual heating profile simulating Mars entry was desired for these tests. The Mars entry heating profile is shown again in Fig. 15 along with the heating pulse used to set the test conditions for the HYMETS tests. For these profiles, the actual Mars entry integrated heat load is $354 \times 10^{6} \mathrm{~J} / \mathrm{m}^{2}$ where the HYMETS heat pulse integrated heat load is $350 \times 10^{6}$ $\mathrm{J} / \mathrm{m}^{2}$, which was considered to be adequate for these tests. Similarly, heat pulses for use in the HYMETS test to represent the other two parametric curves given in Fig. 12 were determined. Table 1 displays the three HYMETS test set conditions. The pressure was set to $0.036 \mathrm{~atm}$, which was the maximum achievable pressure for the facility.

Both PICA and ACC-6 specimens were tested under the three test conditions defined in Table 1. Three replicates were tested for each condition. The standard test assembly used for the tests in shown in Fig. 16. The nominal diameter of all specimens was $25.9 \mathrm{~mm}$. The PICA specimens were 14-mm thick, the maximum specimen thickness permissible with the standard holder allowing for $0.6 \mathrm{~mm}$ of alumina spacer underneath. A 6.5 -mm thick 


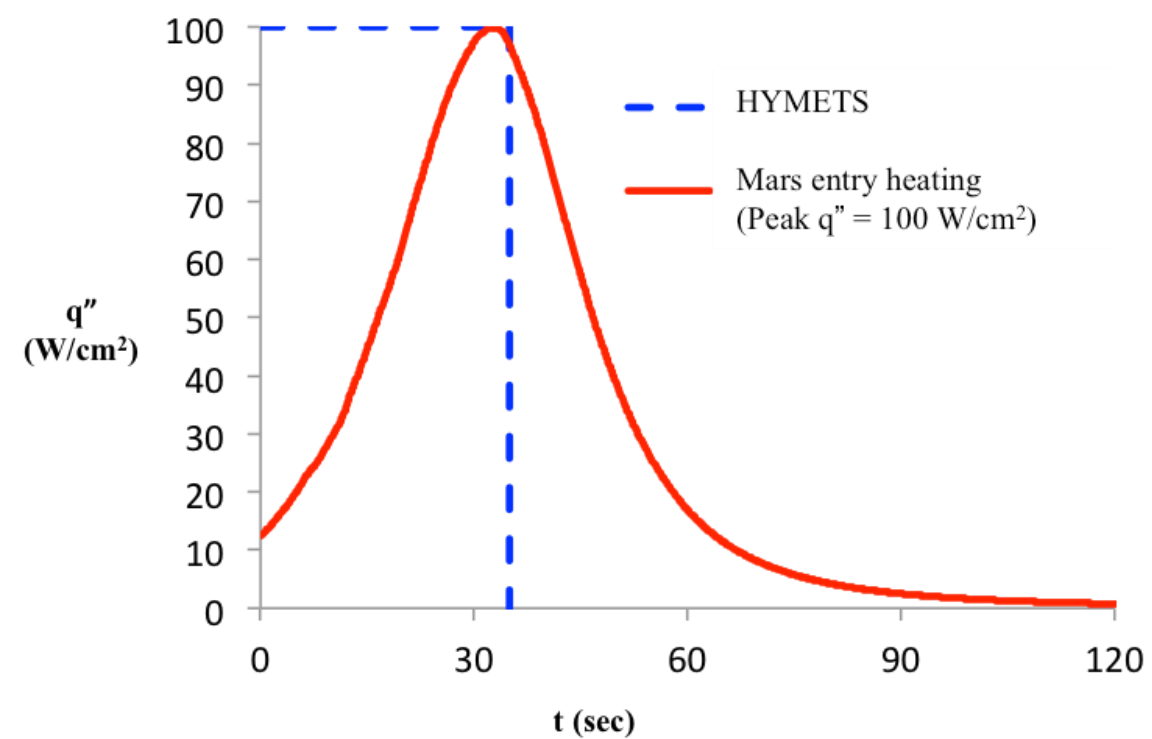

Figure 15. Heat pulse for HYMETS testing.

Table 1. HYMETS Test Set Conditions.

\begin{tabular}{llll}
\hline Set $\#$ & $\mathbf{1}$ & $\mathbf{2}$ & $\mathbf{3}$ \\
\hline Pressure & $0.036 \mathrm{~atm}$ & $0.036 \mathrm{~atm}$ & $0.036 \mathrm{~atm}$ \\
Heat Flux & $100 \mathrm{~W} / \mathrm{cm}^{2}$ & $150 \mathrm{~W} / \mathrm{cm}^{2}$ & $200 \mathrm{~W} / \mathrm{cm}^{2}$ \\
Test Duration & $35 \mathrm{sec}$ & $34 \mathrm{sec}$ & $33 \mathrm{sec}$ \\
\hline
\end{tabular}

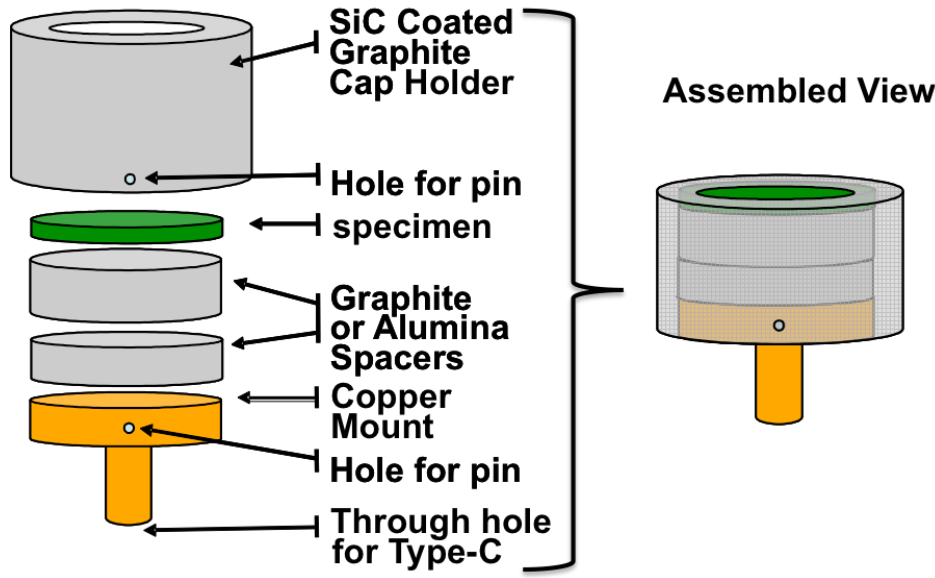

Figure 16. HYMETS test assembly and components.

copper mount was located on the backside. The ACC-6 specimens were $6.35-\mathrm{mm}$ thick with a 0.3 -mm thick layer of alumina, and additional 7.9-mm thick rigid insulation on top of the $6.5-\mathrm{mm}$ thick copper mount. During testing, surface temperature was measured with a pyrometer and backside temperature with a Type-C thermocouple. To measure recession, the thickness of each specimen was measured before and after testing.

Additionally, an alternate assembly holder was investigated for testing ACC-6 samples. The alternate holder was desired to reduce lateral heat conduction from the ACC-6 sample to the graphite holder and thus maintain onedimensional heat transfer for the test. Lateral conduction and heat loss to the holder was an issue for ACC-6 since it 
has a significantly higher in-plane conductivity than PICA. This heat loss was determined to be an issue when lower than expected temperatures were measured for the ACC-6 samples. The alternate holder was made of PICA and did not have the upper lip like the graphite holder. Alternately, the edge of the PICA holder extended $2.54 \mathrm{~mm}$ above the ACC-6 specimen to help hold the specimen in place as the PICA holder ablates during testing. Using the PICA holder, two ACC-6 replicate specimens were tested at test condition 1 and at test condition 2.

\section{Thermal Analysis and Sizing}

The Fully Implicit Ablation and Thermal Response (FIAT) code ${ }^{21}$ was used to perform thermal analysis and sizing. FIAT is a one-dimensional ablation, thermal analysis, and sizing code which contains a material property database that includes most of the materials of interest for this study. Within FIAT, material recession is also predicted in the ablating materials modeled. FIAT was used first to predict the HYMETS test results and thus establish the use of FIAT for further use in thermally sizing the insulation needed for the Mars entry application.

For the HYMETS test, the analysis models included the thickness of the test specimen, insulation, and copper, with thickness values given in the prior section. The HYMETS test set conditions given in Table 1 were used to create relevant environment profiles for input with FIAT. The actual test gas composition was also input into FIAT to predict the thermal response of the test specimens. HYMETS simulates the Mars atmosphere using the test gas composition of 5\% argon, $27.8 \%$ nitrogen, $0.8 \%$ oxygen, and $66.4 \%$ carbon dioxide. Measured results included surface temperature, backside temperature, and material recession.

FIAT was then utilized to perform thermal analysis and sizing using the three heating profile parametric curves given in Fig. 10-c. The tail of the curves in Fig. 10-c was extended to include the duration of 239 sec, where the heatshield is jettisoned at this time. The actual Martian atmosphere gas composition was input into FIAT for this analysis: $1.6 \%$ argon, $2.7 \%$ nitrogen, $0.1 \%$ oxygen, and $95.3 \%$ carbon dioxide. Both the baseline and HOST concept were analyzed and sizing of the insulation material was performed. For the baseline thermal model, existing FIAT material properties were used for modeling PICA, RTV, and aluminum honeycomb, where for the M55J face sheets, the existing properties of graphite bismaleimide (BMI) were used and adjusted for the M55J density values. Thermal analyses were performed for the baseline where the PICA thickness was sized for the three heating profiles enforcing a temperature constraint of $250^{\circ} \mathrm{C}$ at the PICA/RTV interface.

For the HOST concept thermal model, ACC-6 was modeled using existing FIAT ablation properties for reinforced carbon-carbon (RCC) with recent ACC-6 properties to comprise an ACC-6 material model. Opacified Fibrous Insulation (OFI) material was chosen for the insulation material where thermal properties had been developed at NASA LaRC. ${ }^{22} \mathrm{OFI}$ is efficient in reducing radiation which is the dominant mode of heat transfer at higher temperatures; consequently, OFI was chosen as the only insulation layer for Mars entry since the heatshield is jettisoned while temperatures are still high. A thin bottom layer $(0.51 \mathrm{~mm})$ of Nextel 440 fabric was included in the model for holding the OFI insulation in place between the ACC- 6 and fabric. The fabric was modeled as a heat sink, with no heat loss from the backside, which is a conservative assumption. The OFI thickness was sized based on Nextel fabric IML temperature constraint of $150^{\circ} \mathrm{C}$. Parametric studies were also conducted with IML temperature constraints varying between $200^{\circ} \mathrm{C}$ to $300^{\circ} \mathrm{C}$. As expected, insulation thickness and mass decreased with increasing IML temperature constraint. Only results with IML temperature constraint of $150^{\circ} \mathrm{C}$ are shown in this paper, and these results are the most conservative set of results.

\section{Thermal Results: HYMETS Test and Analysis Comparison}

The HYMETS testing was completed as described in the previous section for the three set test conditions listed in Table 1 when the graphite specimen holder was used. Data shown for the graphite holder are the average of the three specimens tested. All PICA specimens were tested in the graphite holder. In addition to the tests in the graphite holder, additional ACC-6 specimens were tested using the alternative specimen holder made from the PICA material as also described in the previous section. Due to thermocouple mounting issues, the backside temperature data were not considered reliable and will not be presented. Thermal analysis using FIAT was performed to evaluate the HYMETS test results.

The PICA specimens surface temperature measurements gathered during testing in HYMETS using the pyrometer are compared to the FIAT analysis predictions in Fig. 17. Shown in the figure are just the results for test condition 1 and 3. The predictions are presented with solids lines, while measurements are displayed with dashed lines. Data for test condition 2 fell in between these two sets of data and are not included in the figure since the behavior was similar. As can be observed in the figure for both conditions, the surface temperature of the PICA specimens rises rapidly initially and then becomes very stable after about $5 \mathrm{sec}$. The difference between the test and analysis can possibly be attributed to uncertainties associated with both FIAT thermal predictions and the pyrometer 
measurements. Another possible explanation could be that PICA is losing heat laterally to the graphite model holder; deviating from onedimensional (through thickness) heat transfer behavior, which is used in the FIAT model. This explanation is plausible in that the measured temperatures are lower than predicted. The root mean square (rms) deviations between measurements and predictions were $162.9^{\circ} \mathrm{C}, 215.9^{\circ} \mathrm{C}$, and $241.5^{\circ} \mathrm{C}$ for test conditions 1 through 3 , respectively, between 5 seconds and the end of each test; the data from the first $5 \mathrm{sec}$ were not considered because of pyrometer nonresponsiveness below $1000^{\circ} \mathrm{C}$. Considering that the maximum predicted surface temperatures for these tests were $1690^{\circ} \mathrm{C}$, $1810^{\circ} \mathrm{C}$, and $1989^{\circ} \mathrm{C}$, the corresponding ratio of rms deviations to maximum temperatures ranged between $9.6 \%$ to $12.1 \%$. Considering experimental and thermal modeling uncertainties, these deviations may be considered reasonable.

Both a pre- and post-test photograph of a PICA specimen tested under the most severe Condition 3 , where the heat flux was set at $200 \mathrm{~W} / \mathrm{cm}^{2}$ for $33 \mathrm{sec}$, is given in Fig. 18. As can be observed in the photo, the specimen became charred during testing. This was the case for all three test conditions and thus only the photograph of the most severe test condition is given here. For PICA tested in the graphite holder, the outer edges/perimeter of the specimen was shielded under the lip of the graphite holder resulting in minimal recession under the holder with the rest of the specimen exhibiting almost uniform recession. The comparison of PICA measured and predicted recessions using FIAT for test conditions 1 through 3 are presented in Fig. 19. As can be observed for the lowest heat flux test case, the predicted recession matched the test results well. However, as the heat flux increased, the difference between measured and predicted also increased with the predicted recession being significantly lower than measured. This is interesting since the predicted surface temperatures were higher, which would lead to greater recession. Consequently, the ability for FIAT to predict the HYMETS test results appears to deteriorate as heat flux increases. However, considering experimental and thermal modeling uncertainties, with the difference being $0.5 \mathrm{~mm}$ at test condition 3 , these deviations may be considered reasonable.

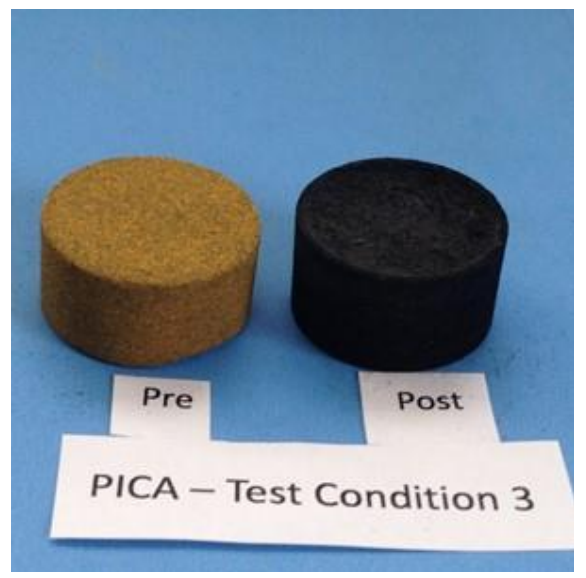

Figure 18. Pre- and post-test photographs of PICA specimens for test condition 3 .

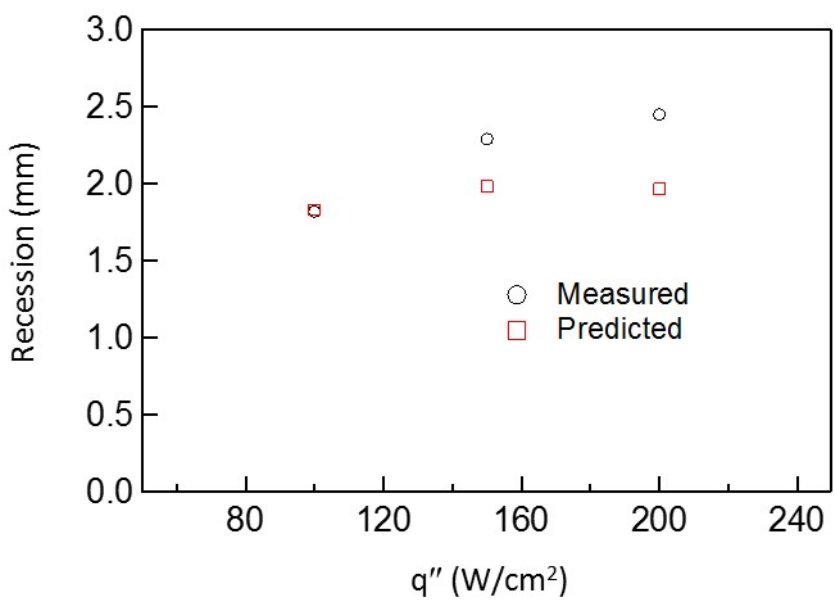

Figure 19. Recession in PICA specimens.

For the ACC-6 specimens tested in the graphite holder, surface temperature measurements gathered during testing in HYMETS are compared to the FIAT analysis predictions in Fig. 20 for test condition 3. Note the pyrometer used for measuring surface temperature only operates above approximately $1000^{\circ} \mathrm{C}$, therefore, it provides a flat $1000^{\circ} \mathrm{C}$ 
reading until the target temperature exceeds this threshold. As can be seen in the figure, the predicted surface temperatures are significantly higher than the measured temperatures. Predicted surface temperatures were also significantly higher than measured for the other two test conditions not shown. The low measured temperatures were concluded to be due to significant lateral heat losses to the graphite model holder because of very high inplane thermal conductivity of ACC-6 (5 to 10 times higher than its through-the-thickness thermal conductivity). ACC-6 did not heat up as rapidly as PICA had done as shown in Fig. 15 and the rms deviations between measurements and predictions were $418^{\circ} \mathrm{C}$, $436^{\circ} \mathrm{C}$, and $471^{\circ} \mathrm{C}$ for test conditions 1 through 3 , respectively, with the rms differences calculated from the moment the pyrometer reading exceeded $1000^{\circ} \mathrm{C}$ until the end of the test. These differences are twice as much as the PICA differences. Consequently, the use of the graphite holder for testing ACC-6 was concluded to be questionable and an alternative test holder was desired. This led to the decision to attempt testing using PICA, a highly insulative material for the holder material, since this would negate or lessen a lateral conduction issue. PICA holders were machined and two ACC-6 specimens were tested, one at condition 1 and the other at condition 2 .

Using the PICA holder, the surface temperature measurements gathered during testing in HYMETS are compared to the FIAT analysis predictions in Fig. 21 for test condition 1 and 2 . The predictions are presented with solids lines, while measurements are displayed with dashed lines. No data were generated for test condition 3 . The surface temperatures showed an abnormal initial abrupt rise and drop for both test conditions. This had not been observed on any of the previous tests using the graphite model holder. The cause of this observed anomaly is not clear. If the pyrometer measurement anomalies around $10 \mathrm{sec}$ are ignored, the predictions and measurements of ACC-6 surface temperatures are in close agreement. The rms difference between predicted and measured surface temperatures for test conditions 1 and 2 were $31.6^{\circ} \mathrm{C}$ and $82.6^{\circ} \mathrm{C}$, respectively, between $10 \mathrm{sec}$ and the end of the test. The correlation is significantly better than ACC- 6 test results in the graphite model holder, and even better than PICA results in the graphite model holder. This close agreement between predictions and measurements of surface temperatures in the PICA model holder implies that use of the PICA model holder has resulted in minimizing lateral heat losses from the ACC-6 samples to the model holder, therefore, resulting in higher and more realistic surface temperatures.

A post-test photograph of the ACC-6 specimen still mounted in the PICA model holder after testing at the nominal heat flux of $100 \mathrm{~W} / \mathrm{cm}^{2}$ (test condition 1) is shown in Fig. 22. As can be observed in the figure, the PICA holder charred and receded around the ACC-6 sample. Where at pre-test the holder extended $2.54 \mathrm{~mm}$ above the specimen, the PICA holder is slightly below the outer surface of ACC-6 post-test. Pre- and post-test photographs of the ACC-6 sample exposed to test condition $2\left(150 \mathrm{~W} / \mathrm{cm}^{2}\right)$ in the PICA model holder are shown in Fig. 23. The recession is very uniform across the surface, because the entire surface was exposed to flow while for tests in the graphite holder, the edges of the samples were shielded from the flow by the lip of the model holder and those 
specimens had a concave surface post-test (not shown). The comparison of ACC-6 measured in the PICA holder and predicted recessions using FIAT for test conditions 1 and 2 are presented in Fig. 24. The difference between predictions and measurements was $0.05 \mathrm{~mm}$ and $0.1 \mathrm{~mm}$ for test conditions 1 and 2, respectively. Comparing recessions for PICA and ACC-6 from Figs. 19 and 24, recession for ACC-6 is significantly less than for PICA; PICA had measured recessions of $1.8 \mathrm{~mm}$ and $2.3 \mathrm{~mm}$ while ACC-6 had measured recessions of $0.18 \mathrm{~mm}$ and $0.32 \mathrm{~mm}$ for test conditions 1 and 2, respectively. In general, the PICA holder appears to have achieved the expected and desired result; a PICA holder is a good solution to achieving a more one-dimensional heat transfer for HYMETS specimens. Furthermore, the close agreement in both the surface temperatures and recession also validates the ACC-6 model used in FIAT.

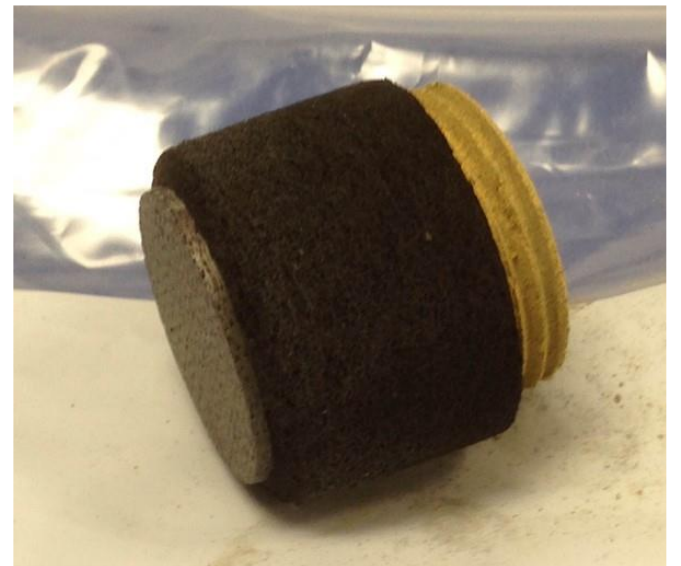

Figure 22. Post-test ACC-6 specimen mounted in a PICA holder (test condition 1).

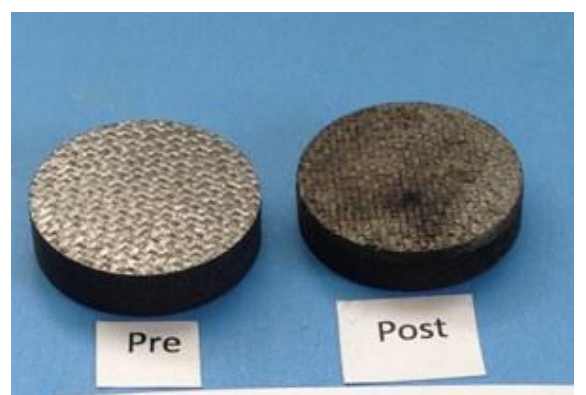

ACC-6 - Test Condition 2 (PICA Model Holder)

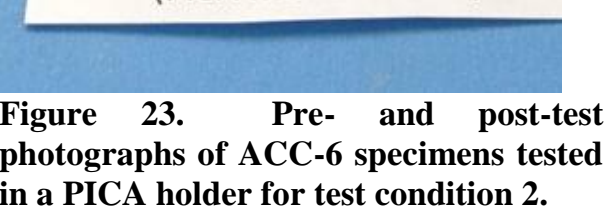

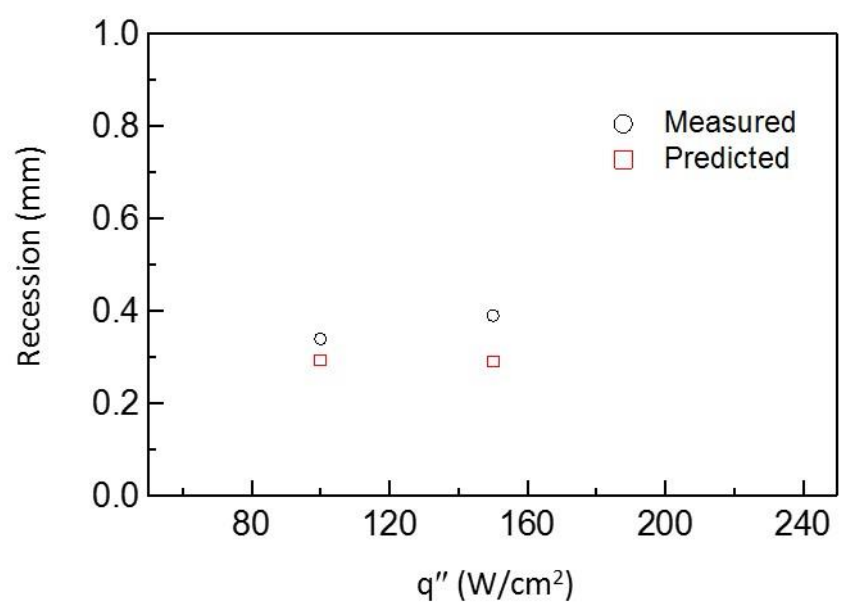

Figure 24. Recession in ACC-6 specimens (measured in PICA holder)

\section{E. Thermal Sizing Results}

Having achieved good correlation between the HYMETS measurements and FIAT analysis predictions, sufficient confidence was achieved on the FIAT models for both PICA and ACC-6 to perform a thermal sizing of both the baseline and HOST concepts for the Mars entry conditions and to accurately compare the baseline and HOST concept in a trade study. FIAT was utilized to perform thermal sizing of both the baseline and HOST concept using the three heating trajectories given in Fig. 12. The tail of the curves in Fig. 12 was extended to include the duration of $239 \mathrm{sec}$, where the heatshield is jettisoned at this time. For the baseline, the PICA insulation was sized to maintain the specified $250^{\circ} \mathrm{C}$ constraint at the PICA/RTV interface and the honeycomb sandwich structure with RTV remained constant at $6.482 \mathrm{~cm}$. For the HOST concept, the required thickness of OFI was sized to maintain the specified $150^{\circ} \mathrm{C}$ temperature constraint on Nextel fabric and the thickness of the other components of the HOST heatshield (ACC-6 and Nextel fabric) remained constant at $0.686 \mathrm{~cm}$. The insulation thickness results are displayed in Fig. 25. As can be observed in the figure, the required thickness of PICA for the baseline concept is higher than the required thickness of the internal blanket insulation, OFI for the HOST concept. The difference in the required PICA thickness for the baseline also increases somewhat with increasing peak heat flux and integrated heat load, where as shown in Fig. 25 for $200 \mathrm{~W} / \mathrm{cm}^{2}$ peak heat flux, PICA required thickness is $2.35 \mathrm{~cm}$, which is $54 \%$ greater 
than the OFI insulation thickness of $1.53 \mathrm{~cm}$ required for the HOST concept. Additionally, the predicted PICA thicknesses are significantly lower than the actual PICA thickness of $3.175 \mathrm{~cm}$ used on the MSL heatshield. The thicker PICA for the actual flight vehicle heatshield may have included significant margins or was sized for higher heat fluxes than were later determined to occur during the MSL flight. The comparison of predicted recessions for both the baseline and HOST concept as a function of peak heat flux is shown in Fig. 26. FIAT predicts recession in the OML materials, which is PICA on the baseline concept and ACC-6 on the HOST concept. The predicted ACC- 6 recessions varied between 0.81 and $1.62 \mathrm{~mm}$, significantly lower than predicted PICA recessions of $5.1 \mathrm{~mm}$ to $10.8 \mathrm{~mm}$. This result signifies the value of using of ACC- 6 on the OML of heatshields where greater dimensional stability is

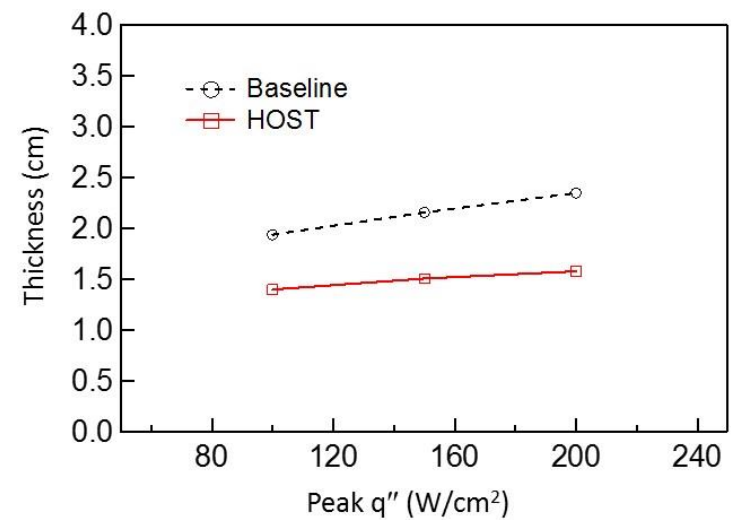

Figure 25. Insulation thicknesses sized for Mars heating trajectories.

desired to reduce uncertainty and complexity in predicting vehicle performance. The comparison of peak surface temperatures for both concepts as a function of trajectory peak heat flux is provided in Fig. 27. ACC-6 peak surface temperatures are lower than PICA, with the difference decreasing with increasing temperature. Comparison of surface temperatures for both concepts as a function of time for trajectory with peak heat flux of $150 \mathrm{~W} / \mathrm{cm}^{2}$ is shown in Fig. 28. ACC-6 has lower surface temperatures compared to PICA during the heating portion of trajectory, but has higher values during the cooling portion. The in-depth variation of temperature with time for trajectory with peak heat flux of $150 \mathrm{~W} / \mathrm{cm}^{2}$ is shown in Fig. 29. The surface temperature, ACC-6 back face temperature at a depth of $0.635 \mathrm{~cm}$, the temperature halfway through OFI thickness at a depth of $1.365 \mathrm{~cm}$, and the OFI/Nextel interface temperature at a depth of $2.09 \mathrm{~cm}$ are plotted with time. During the heating portion of the trajectory, the ACC- 6 back face temperature $(0.635 \mathrm{~cm})$ is cooler than the surface temperature. During the cooling portion of trajectory, the back face temperature is slightly higher or equal to surface temperature. Large temperature gradients are maintained across the minimal OFI thickness of $1.46 \mathrm{~cm}$, revealing the superior effectiveness of OFI as an insulation material for a Mars entry application.

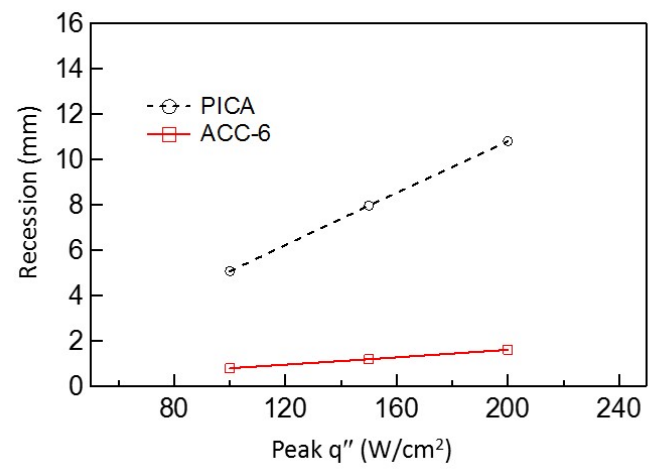

Figure 26. Predicted recession for Baseline (PICA) and HOST (ACC-6) OML materials.

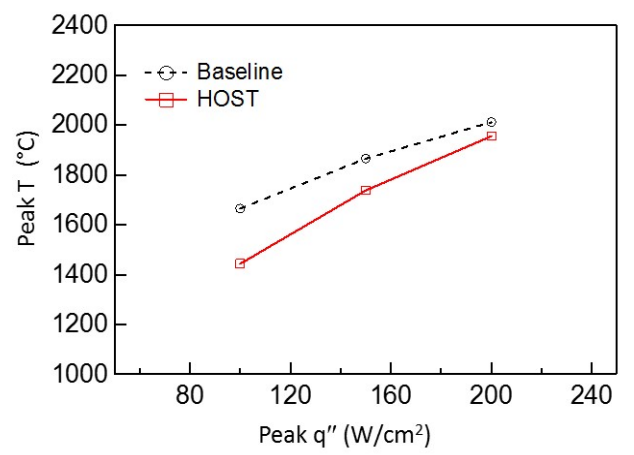

Figure 27. Predicted peak surface temperatures. 


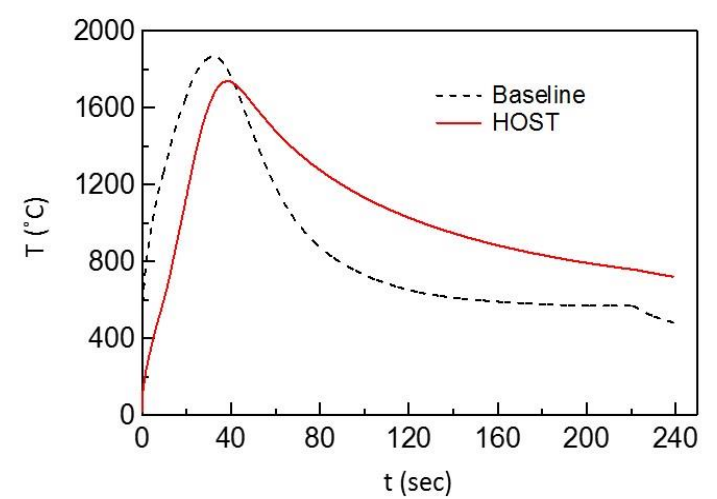

Figure 28. Predicted surface temperatures with time for trajectory with peak heat flux of 150 $\mathrm{W} / \mathrm{cm}^{2}$.

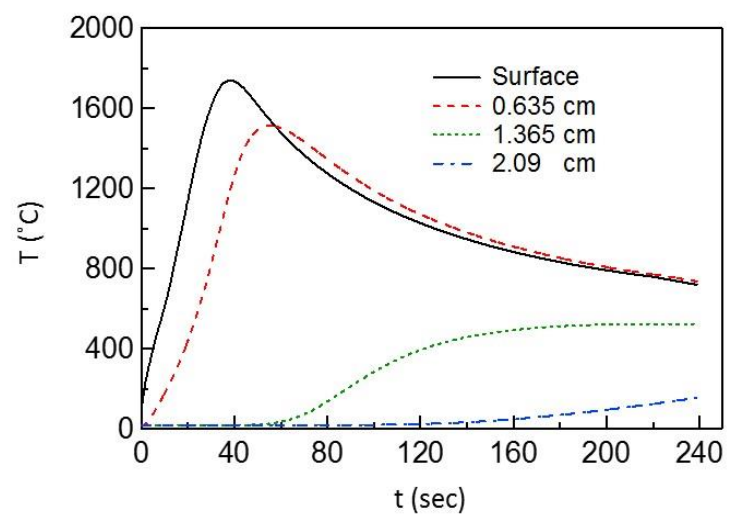

Figure 29. HOST in-depth temperatures as a function of time for trajectory with peak heat flux of $150 \mathrm{~W} / \mathrm{cm}^{2}$.

\section{HOST Entry Thermal Stress Evaluation}

For the MSL heatshield, the 15-g deceleration during entry in the Mars atmosphere was the critical load case. However, for the HOST heatshield, the significant aerothermal heating of the structure also needs to be evaluated to determine if the addition of thermal stresses on the heatshield becomes a critical load case. Although the peak heat flux was predicted to occur very locally in the shoulder region, for this initial assessment of thermal load, spatial variations of the outer surface heat flux was not considered. Only the one-dimensional temperature gradient through the thickness of the ACC-6 predicted with FIAT was assumed to be uniform over the entire outer surface of the heat shield. For the worst-case heating trajectory evaluated, with the peak heat flux being $200 \mathrm{~W} / \mathrm{cm}^{2}$ as shown in Fig. 12 , the peak thermal gradient through the thickness predicted was $591^{\circ} \mathrm{C}$, and occurred when the outer surface temperature was $1136^{\circ} \mathrm{C}$ and the inner surface temperature was $545^{\circ} \mathrm{C}$. For simplicity, this thermal load was applied to the HOST structural model as a linear thermal gradient through the thickness of the shell elements for the entire HOST heatshield. The resulting displacements for this thermal load case are shown in Fig. 30. The peak displacement was $0.079 \mathrm{~cm}$ in the displacement magnitude plot, which is less than the displacements that occurred for the 15-g load case. The thermal loading also produced a minimum margin of safety of MS $=3.47$, greater than the minimum MS $=0.3$ for the 15 -g load case. Next, a combined load case of the 15 -g descent pressure plus the thermal load was applied. The results for the thermal load only and combined load cases are given in Fig. 31 and the contours are shown using the same scale as in Fig 8. Interestingly, the combined effect of the $15-\mathrm{g}$ and thermal load yielded greater MS values than the 15 -g alone (Fig. 8). So the effect of the thermal load actually lessened the total load on the heatshield; where the 15-g load provided for a compressive response on the outer surface, the thermal load put the outer surface in tension, and thus the net effect of the 15-g load and thermal load is lower overall stresses on the heatshield than for the $15-\mathrm{g}$ load only.

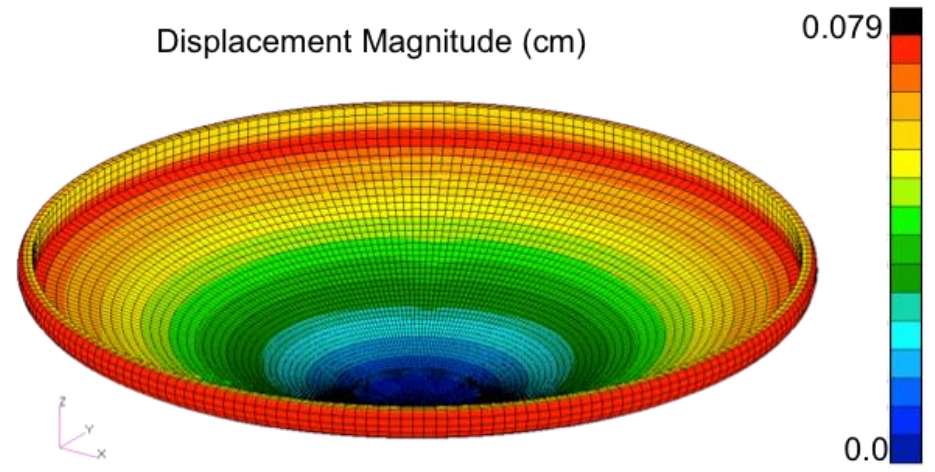

Figure 30. Displacement magnitude for the thermal load case. 


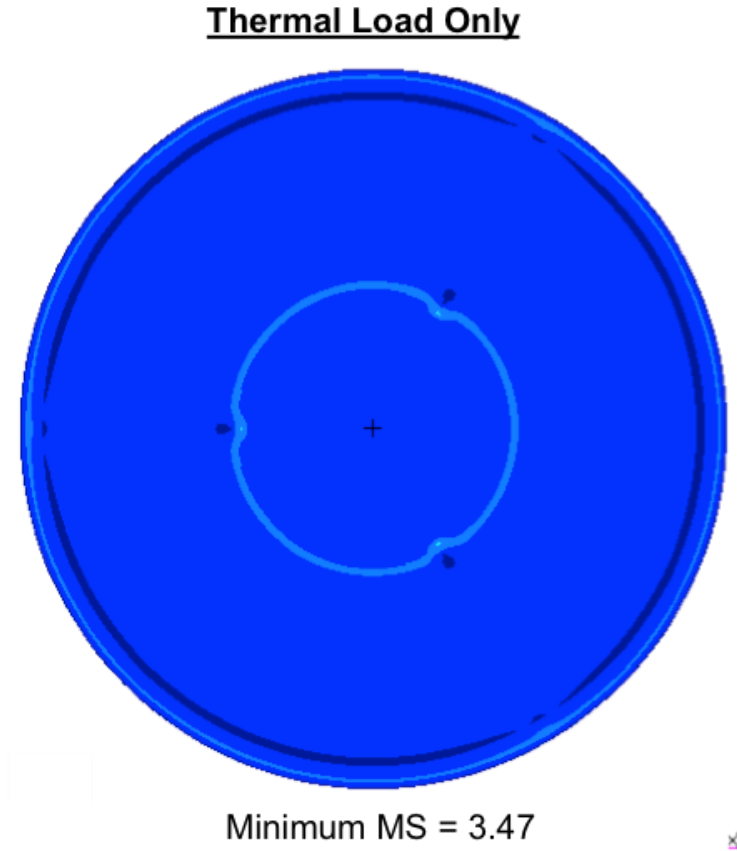

(a)
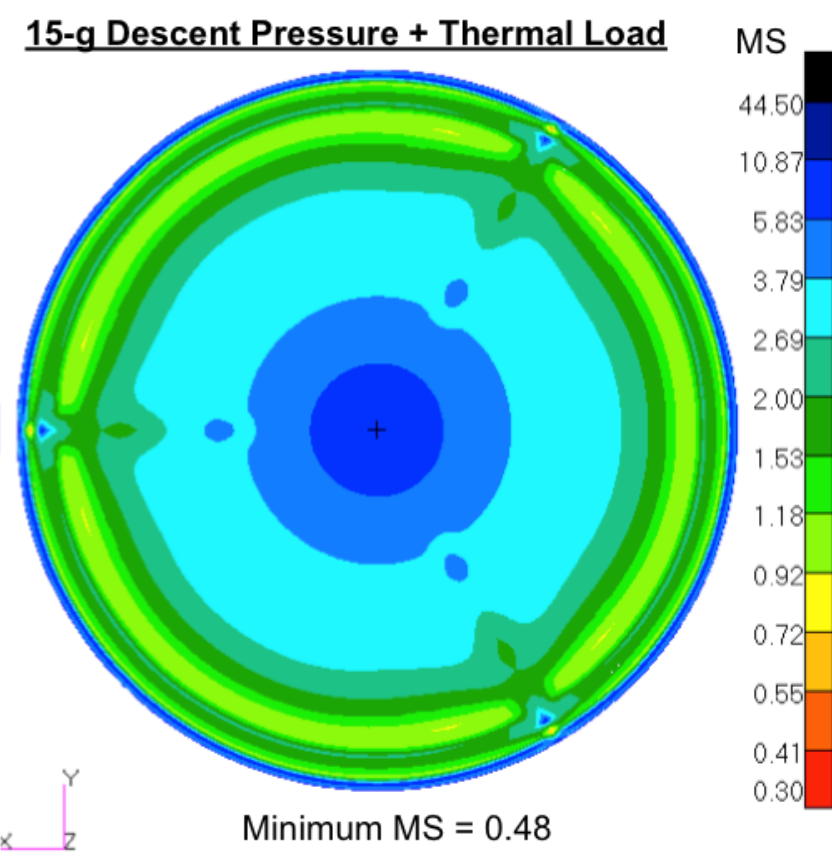

(b)

Figure 31. Margin of safety contour plots for the (a) thermal load and (b) combined load case.

\section{Integrated Thermal-Structural Results and Discussion}

The development of a multifunctional HOST heatshield for a Mars entry application has initiated with considering both structural and thermal performance. Results from the initial structural study were included in the thermal model to evaluate thermal performance and perform sizing of the thermal insulation. Thermal analysis results were then utilized to define the thermal load used to further evaluate the structural performance of the HOST concept when subjected to combined thermal and structural loads. The integrated thermal-structural design results, although preliminary, are evidence of the potential of the HOST concept.

The heatshield thickness results for the three heating trajectories evaluated are given in Table 2. The thickness of the structure for the baseline includes the composite sandwich layers which are comprised of two M55J facesheets and a honeycomb core. For the HOST concept, the thickness of the structure includes the thickness of the ACC-6 outer skin and inner flange. The insulation thicknesses for the HOST concept are greater than the web height used

Table 2. Mars Entry heatshield thicknesses (cm)

\begin{tabular}{|c|c|c|c|c|c|c|}
\hline \multirow[b]{3}{*}{$\begin{array}{c}\text { External } \\
\text { TPS }\end{array}$} & \multicolumn{2}{|c|}{ Peak q" $=100 \mathrm{~W} / \mathrm{cm}^{2}$} & \multicolumn{2}{|c|}{ Peak q" $=150 \mathrm{~W} / \mathrm{cm}^{2}$} & \multicolumn{2}{|c|}{ Peak q" $=200 \mathrm{~W} / \mathrm{cm}^{2}$} \\
\hline & Baseline & $\begin{array}{c}\text { HOST } \\
\text { concept }\end{array}$ & Baseline & $\begin{array}{c}\text { HOST } \\
\text { concept }\end{array}$ & Baseline & $\begin{array}{c}\text { HOST } \\
\text { concept }\end{array}$ \\
\hline & 1.94 & none & 2.16 & none & 2.35 & none \\
\hline Adhesive & 0.03 & none & 0.03 & none & 0.03 & none \\
\hline Structure & 6.452 & 1.27 & 6.452 & 1.27 & 6.452 & 1.27 \\
\hline $\begin{array}{c}\text { Internal } \\
\text { Insulation }\end{array}$ & none & 1.401 & none & 1.511 & none & 1.581 \\
\hline TOTAL & 8.422 & 2.671 & 8.642 & 2.781 & 8.832 & 2.851 \\
\hline$\%$ Difference & \multicolumn{2}{|c|}{215} & \multicolumn{2}{|c|}{211} & \multicolumn{2}{|c|}{210} \\
\hline
\end{tabular}


in the structural analysis, so no additional web height needs to be accounted for in evaluating overall thickness. The internal insulation thickness for HOST includes the OFI and Nextel fabric layers. There is significant volumetric efficiency associated with the use of HOST compared to the traditional, baseline design approach. The difference is over $200 \%$ for the three cases evaluated. Note that no margins were applied to the TPS or insulation for this comparison, however, considering uniform thermal margins should not skew these findings. As an example using the median peak heat flux case of $150 \mathrm{~W} / \mathrm{cm}^{2}$ and considering the actual thickness of the PICA TPS on MSL being $3.175 \mathrm{~cm}$, this equates to approximately a 1.5 factor of safety applied to the PICA thickness. Applying this factor of safety to the OFI insulation on the HOST concept yields an OFI thickness of $2.27 \mathrm{~cm}$. A comparison of the overall heatshield thickness is given in Fig. 32, where actual thickness values are shown for the two concepts. Here, the baseline is the actual thickness of the MSL heatshield and is being compared to a design of a HOST concept developed under the same requirements. Note that, in actual practice, the factor of safety could be applied to the heating and was applied here to the TPS thickness for simplicity to quickly perform a uniform trade study of the concepts and be able to include the overall thickness of the actual MSL design. From this figure, the significance on the thickness due to the traditional design approach is overwhelming, i.e., using an ablating TPS material of substantial thickness along with requiring a substantially thick structure to minimize bending and essentially eliminate any load transfer to the brittle TPS material, is indeed volumetrically inefficient. This is not an issue with the HOST concept that does not use brittle TPS material. A significantly less thick structure using ACC-6 is sufficient to meet the structural requirements for a Mars entry application. These results clearly reveal volumetric advantage associated with the HOST concept.

Also shown in Fig. 32 is the CG as computed from the OML for the baseline and HOST concept. The CG associated with the baseline heatshield is $3.03 \mathrm{~cm}$ from the OML, where the CG for the HOST concept is only $0.56 \mathrm{~cm}$ from the OML. This CG translation for the HOST concept, with the CG being nearly $2.5 \mathrm{~cm}$ closer to the OML than for the baseline, may provide advantages for precision landing and should be noted when considering the benefits of the HOST concept.

A comparison of mass per unit area for the case of the baseline and HOST concepts compared in Fig. 32 is given in Table 3. The structural mass per unit area for the HOST concept includes the ACC- 6 skin and the frame components. For the baseline, the mass of the external TPS dominates the mass of the heatshield, where although the structure is lightweight compared to the HOST structure, the internal insulation for the HOST concept is extremely efficient in providing the insulation needed to meet the internal temperature requirement. Overall, a mass savings of nearly 30 percent appears achievable for the HOST concept compared

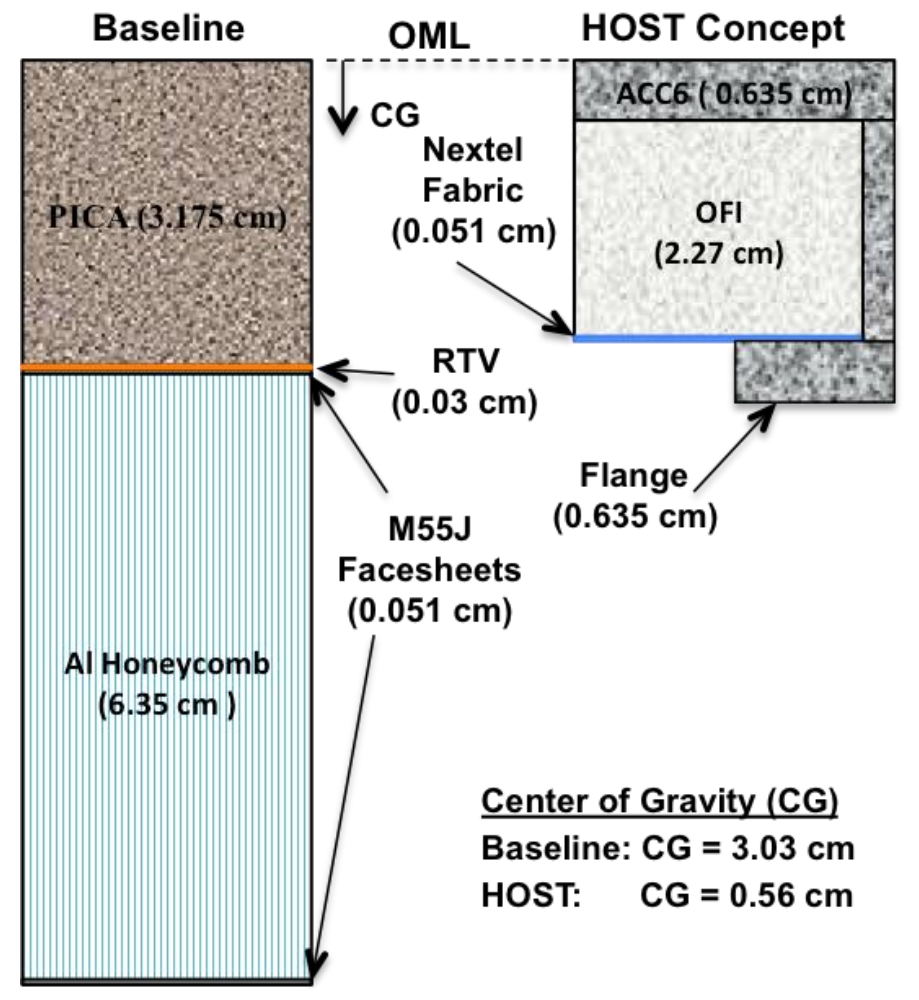

Figure 32. Thickness and CG comparison with 1.5 factor of safety applied to insulation thickness for a peak heating of $150 \mathrm{~W} / \mathrm{cm}^{2}$.

Table 3. Heatshield mass per unit area $\left(\mathrm{kg} / \mathrm{m}^{2}\right)$

\begin{tabular}{|c|c|c|}
\hline & Baseline & HOST concept \\
\hline $\begin{array}{c}\text { External } \\
\text { TPS }\end{array}$ & 14.99 & none \\
\hline Adhesive & 0.43 & none \\
\hline Structure & 6.33 & 10.54 \\
\hline $\begin{array}{l}\text { Internal } \\
\text { Insulation }\end{array}$ & none & 4.87 \\
\hline TOTAL & 21.74 & 15.40 \\
\hline$\%$ Difference & & 29 \\
\hline
\end{tabular}


to the traditional, baseline design for a Mars entry application.

Based on the overall results of this study, the HOST heatshield concept could be a feasible and attractive alternative to the traditional baseline design for Mars entry heatshields. There was minimal deviation for the behavior of the HOST heatshield compared to the baseline heatshield behavior, indicating the possibility that HOST could easily be substituted for a heatshield on a similar Mars entry mission. Interestingly, both the baseline and HOST heatshield results revealed that the most significant deformation occurred in the cone section of the heatshield. Consequently, if structural behavior was considered in defining the shape of the heatshield, a spherical shaped heatshield, similar to that used on Earth-return missions, should yield a more optimal structural concept, and should be considered on future planetary entry vehicles.

\section{Concluding Remarks}

Development of a multifunctional hot structure (HOST) heatshield concept has continued with the current focus on a Mars entry mission. Considering both the thermal and structural performance demonstrated in this study, the HOST concept appears to be a feasible alternative to a traditional heatshield for Mars entry applications. The potential for the HOST concept to significantly save both weight and volume compared to a traditional Mars entry heatshield, while offering other benefits including less recession, has been revealed. Also, during this study, the importance of the holder material used for HYMETS arc-jet testing was observed for test specimens with significantly high in-plane conductivity; the holder needs to be sufficiently insulative to limit conduction from the specimen to the holder and thus provide a somewhat one-dimensional test condition for evaluating material response and comparing to one-dimensional analysis predictions.

Overall, further evaluation is recommended to mature the HOST concept using a building block approach. Systematically adding detail to the analysis model should include performing aerothermal analysis to: evaluate the effect of the actual spatially varying temperature distributions and determine if thermal stresses becomes a critical design driver. Also, the design of joints needs to be addressed in the progression towards subcomponent testing. As future mission requirements become better defined, a multifunctional hot structure heatshield, including a rigid deployable system, may be an enabling concept.

\section{Acknowledgments}

The authors would like to acknowledge Theodore Johnson, Head, Structural Mechanics and Concepts Branch, W. Keith Belvin, Senior Technologist for Structures and Thermal Systems, Jean-François Barthelemy, Chief Technologist, and members of the Langley Technology Council (LTC) for providing the funding, support, and oversight for this Internal Research and Development (IRAD) project.

\section{References}

${ }^{1}$ Laub, B., and E. Venkatapathy. "Thermal protection system technology and facility needs for demanding future planetary missions." Planetary Probe Atmospheric Entry and Descent Trajectory Analysis and Science. Vol. 544. 2004.

${ }^{2}$ Edquist, K.cT., Dyakonov, A.cA., Wright, M.J. and Tang, C.cY., "Aerothermodynamic Design of the Mars Science Laboratory Heatshield," AIAA Paper 2009-4075, AIAA Thermophysics Conference, San Antonio, Texas, 2009.

${ }^{3}$ Wright, M., Beck, R., Edquist, K., Driver, D., Sepka, S., and Slimko, E., "Sizing and Margins Assessment of the Mars Science Laboratory Aeroshell Thermal Protection System," AIAA Paper 2009-4231, AIAA Thermophysics Conference, San Antonio, Texas, June 2009.

${ }^{4}$ Bose, David M., et al. "The Hypersonic Inflatable Aerodynamic Decelerator (HIAD) Mission Applications Study." AIAA Aerodynamic Decelerator Systems Technology Conference and Seminar, Daytona Beach, FL. 2013.

${ }^{5}$ Zang, T.A. et al., "Overview of the NASA Entry, Descent and Landing Systems Analysis Study," AIAA Space 2010 Confernce and Exposition, Anaheim, CA, AIAA-2010-8649, 2010.

${ }^{6}$ Cruz-Ayoroa, et al., "Mass Model Development for Conceptual Design of a Hypersonic Rigid Deployable Decelerator," International Planetary Probe Workshop, Toulouse, France, 2012.

${ }^{7}$ Walker, S. P. et al., "Preliminary Development of a Multifunctional Hot Structure Heatshield," 55 th AIAA/ASME/ASCE/AHS/ASC Structures, Structural Dynamics, and Materials Conference,AIAA 2014-0350, National Harbor, Maryland, 2014.

${ }^{8}$ Williams, S. D., et al. "Thermal protection system design studies for lunar crew module." Journal of Spacecraft and Rockets 32.3 (1995): 456-462. 
${ }^{9}$ Thompson, J.., "Final Report, $3000^{\circ} \mathrm{F}$ Carbon-Carbon Materials for Falcon Leading Edges," Carbon-Carbon Advanced Technologies, Inc., Fort Worth, TX, March 2006.

${ }^{10}$ Glass, D. E., Dirling, R., Croop, H., Fry, T. J., and Frank, G. J., “ Materials for Hypersonic Flight Vehicles,” AIAA-20068122, AIAA/AHI International Space Planes And Hypersonic Systems And Technologies Conference, Volume 3, Canberra, Australia, November 2006.

${ }^{11}$ Vaughn, W., "Flexure Testing of ACC-6 Carbon-Carbon Composites with Stage Bonds," Quick Look Report, NASA Langley Research Center, Hampton, Virginia, March 2014 (unpublished).

${ }^{12}$ Bose, D., White, T., Santos, J. A., Feldman, J., Mahzari, M., Olson, M., and Laub, B.. Initial Assessment of Mars Science Laboratory Heatshield Instrumentation and Flight Data. AIAA Paper, 908, 2013.

${ }^{13}$ Way, D. W., Powell, R. W., Chen, A., Steltzner, A. D., San Martin, A. M., Burkhart, P. D., and Mendeck, G. F., "Mars Science Laboratory: Entry, Descent, and Landing System Performance,” In Aerospace Conference, 2007 IEEE (pp. 1-19). IEEE, 2007, March.

${ }^{14}$ Anon., MSC Nastran 2012.2 Quick Reference Guide, MSC Software Corporation, Santa Ana, CA, 2012.

${ }^{15}$ Schoenenberger, M., Van Norman, J. W., Dyakonov, A. A., Karlgaard, C. D., Way, D. W., and Kutty, P., "Assessment of the Reconstructed Aerodynamics of the Mars Science Laboratory Entry Vehicle," 23rd AAS/AIAA Space Flight Mechanics Meeting, AAS 13-306, 2013.

${ }^{16}$ Sepka, S., and Wright, M. J., "FIAT Uncertainties Using a Monte-Carlo Approach: Improvements and Results for MSL," In 41st AIAA Thermophysics Conference, June 2009.

${ }^{17}$ Beck, R. A., Driver, D. M., Wright, M. J., Hwang, H. H., Edquist, K. T., and Sepka, S. A., "Development of the Mars Science Laboratory Heatshield Thermal Protection System," Journal of Spacecraft and Rockets, 1-12, 2014.

${ }^{18}$ The Boeing Company, "Delta IV Payload Planners Guide,” MDC 99H0065, Huntington Beach, CA, October 1999.

${ }^{19}$ Sutton, K., and Graves, R. A., Jr., "A General Stagnation-Point Convective-Heating Equation for Arbitrary Gas Mixtures," NASA Technical Report R-376, November 1971.

${ }^{20}$ Splinter, S. C., Bey, K. S., and Gragg, J. G., "Comparative Measurements of Earth and Martian Entry Environments in the NASA Langley HYMETS Facility,” AIAA-2011-1014, Aerospace Sciences Meetings, January, 2011.

${ }^{21}$ Chen, Y. K. and Milos, F. S., "Ablation and Thermal Response Program for Spacecraft Heatshield Analysis," Journal of Spacecraft and Rockets, Vol. 36, No. 3, May-June 1999, pp. 475-483.

${ }^{22}$ Daryabeigi, K., Cunnington, G. R., Miller, S. D., and Knutson, J. R., "Combined Heat Transfer in High-Porosity HighTemperature Fibrous Insulations: Theory and Experimental Validation,” AIAA Paper 2010-4660, June 2010. 